\title{
Being small at the right moment: Path dependence after a shift in the technological regime
}

Jasper Hepp 


\title{
Being small at the right moment: Path dependence after a shift in the technological regime
}

\author{
Jasper Hepp* \\ Bielefeld University
}

December 18, 2020

\begin{abstract}
This paper explores the impact of technological change on industry concentration and the underlying firm dynamics. In the agent-based model EURACE@Unibi I implement a paradigm shift in the technological frontier - a shift from a slow to a fast growing regime. The analysis shows that the acceleration in technological change causes a strong increase in market concentration. The reallocation of market shares towards a few large firms is driven by diverging productivities and skills across firms. An ex-post analysis reveals that after the paradigm shift small, but undervalued firms become the large dominating ones in the long-run. Their success gets initiated by a fortunate outcome on the labor market, which increases their skill level. With the faster technological change, their high skilled workforce incentivizes them to invest at the frontier and to build up the most productive capital stock. A virtuous cycle between their decisions on the labor and capital market further increases the productivity gap towards competitors enabling their rise.
\end{abstract}

JEL Codes: C63, O33, L10

Keywords: Market Concentration, Technological Paradigm Shift, Path Dependency, Firm Determinants, Agent-Based Model

*E-mail: jasper.hepp@uni-bielefeld.de Bielefeld Graduate School of Economics and Management (BiGSEM), Bielefeld University, 33615 Bielefeld, Germany.

I am grateful for the support from Herbert Dawid. Comments by Philipp Harting, Roberta Terranova and Alexandre Carrier and by participants of the GENED Annual Meeting (2020), the GroWinPro Agent-based Model Meeting (2020) and the internal seminar at the Bielefeld University are gratefully acknowledged. This work uses a modified version of the Eurace@Unibi model, developed by Herbert Dawid, Simon Gemkow, Philipp Harting, Sander van der Hoog and Michael Neugart, as an extension of the research within the EU 6th Framework Project Eurace. I thank the Bielefeld Graduate School of Economics and Management (BiGSEM) and the Bielefeld Young Researchers Fund for their financial support. 


\section{Introduction}

Industry concentration increases since the 1980s in the U.S. (Autor et al., 2020; Bessen, 2020) and more recently in Europe (Bajgar et al., 2019). For example, Autor et al., 2020 report an average increase in the fraction of sales of the four largest firms by roughly $5 \%$ in the time span from 1982 to 2012 for the U.S. manufacturing industries. Similarly, Bajgar et al., 2019 provide evidence on Europe and U.S. concluding that 3 out of 4 industries experienced a rise in concentration. In parallel, several studies document an increasing divergence across firms in terms of productivity (Andrews et al., 2015) and skills (Song et al., 2019) as well as a general decline in industry dynamics (Bessen et al., 2020). A few firms operate at the productivity frontier, while the rest of the firm population is left behind. This poses the question on the underlying dynamics that result in this polarization.

This paper gives a detailed picture of one potential explanation to the observed pattern of concentration and polarization, namely an acceleration in technological progress. In particular, I study the impact of technological change in the form of a paradigm shift on industry concentration taking into account the role of firm-level heterogeneity as well as heterogeneously skilled workers. Furthermore, in an in-depth analysis I lay out a detailed picture for the path of the largest firms after the paradigm shift. The channel presented in this paper is that under faster technological change productivities between firms disperse, which in turn reallocates market shares towards frontier firms. Within the model, heterogeneity in productivity arises first, from the endogenous diffusion of new machines offered by a stylized capital good producer to firms, and second, from firms' success on the labor market, on which they compete for workers with heterogeneous skills modeled as different speeds of learning-on-the-job. The complementarity between labor and capital in the production function allows us to examine the interaction of firms' decisions on the labor, capital and product market and I am able to give a rich picture of how a few dominating firms emerge after a shift in the technological regime. Additionally, the accumulative nature of capital as well as of knowledge embodied in workers generates strong path dependencies for firms. This allows us to not only describe mechanisms that lead to concentration, but also to identify determinants that characterize those firms right after the paradigm shift that will dominate the market in the long run.

To analyze the phenomena of rising industry concentration as an emerging property arising under faster technological change within a dynamic framework, I make use of the wellestablished agent-based model Eurace@Unibi (Dawid et al., 2019), which builds on the European project Eurace (Deissenberg et al., 2008). The model is particularly well suited to study the dynamics of market shares under endogenous technological change due to the explicit representation of firms' vintage choice as well as the interconnection of firms' decisions on the labor and capital market through the Leontief production function, but also due to the endogenously emerging market shares. The strongly micro-founded behavioral rules of agents (Dawid and Harting, 2012) and the reproduction of a large set of stylized facts (Dawid et al., 2019) validate 
the model. In addition, the model has not been build to fit any recent trend, but nevertheless demonstrates a good fit to patterns on different levels, i.e. increased industry concentration on the aggregate or a diverging firm population on the industry-level. Rather, the focus of past research building on this model has been mainly on policy analysis in different areas (Dawid et al., 2014; Dawid et al., 2018; Van Der Hoog and Dawid, 2019; Harting, 2020), but also on the effect of networks on inequality dynamics (Dawid and Gemkow, 2014) or the diffusion of competing technologies in the context of climate change (Hötte, 2020a; Hötte, 2020b; Hötte, 2021).

In the EURACE@Unibi model I incorporate a technological paradigm shift. Dosi (1982) was among the first to apply the concept of a paradigm to technological change in the context of one specific industry. Freeman and Perez (1988) generalized the approach and introduced the techno-economic paradigm ${ }^{1}$. Both describe technological change as a continuous process within a given trajectory defined by the specific paradigm. At a certain point in time a disruption in form of a radical invention causes a discontinuity and a new paradigm emerges. As a result technology develops on a new trajectory into a new direction. Along trajectories technological change is incremental following the rhythm of the current paradigm, while during a shift a radical innovation causes a kink. A slowdown in the innovative rate occurs when technologies get mature. The relevant example for the setup is the ICT paradigm initiated in 1971 with the invention of the Intel microprocessor in Santa Clara, CA (Freeman, 2009; Perez, 2010) ${ }^{2}$. The diffusion of the personal computer started and its adoption on a large-scale across many information technology-using industries enhanced the productivities of investing firms (Jorgenson et al., 2008; Draca et al., 2009). The theoretical results are discussed in the light of the empirical literature related to ICT. ${ }^{3}$

I model the paradigm shift in the following way. The technological frontier - the productivity of the best-practice machine - develops according to an exogenous trajectory. New inventions arrive with a fixed probability and are added as new machines with an increased productivity to the set offered to firms. The paradigm shift is implemented as a kink in the trajectory, which shifts onto an accelerated path. At a certain point in time, the simulation splits into (1) the baseline scenario, which continues in the previous trajectory, and (2) the paradigm shift scenario, which experiences a disruption and continues on a steeper trajectory for a fixed

\footnotetext{
${ }^{1}$ See also Perez (1985), Dosi (1988), Perez (2010), and Dosi and Nelson (2013) for more details on technological paradigms and the evolutionist or neo-Schumpeterian approach to technological change in general. In fact, the interpretation of a paradigm in this paper is closer to Perez and her techno-economic paradigm than to Dosi and his micro-technological paradigm. Whereas the first one describes for example the diffusion of ICT or electricity on a broader scale, the latter focuses on one narrow industry like the semiconductor (Dosi and Nelson, 2013). In this sense, the notion of radical innovation in this paper is also related to what has been called a general purpose technology (Bresnahan, 2010). For a critical discussion on this term when analyzing the ICT revolution see Nuvolari (2020).

${ }^{2}$ See Freeman and Louca (2001) for a history of technological change from the industrial to the information revolution, and Bresnahan (2019) for an analysis of the development of technological innovations in the ICT sector.

${ }^{3}$ Here, I would like to point out that this paper focuses on technologies that become part of the capital stock (process innovation) in contrast to innovations used as inputs improving the quality of products (product innovation).
} 
period, before it slows down again and returns to the baseline growth rate. In line with the concept paradigm shift, the technological frontier in the model combines the disruptive nature of a novel technology with the incremental change along trajectories.

The results in this paper contribute a detailed story of endogenous polarization as one potential driver of increasing industry concentration to the (mostly) empirical discussion. Within the model, I show that a phase of acceleration in technological progress implies higher market concentration (Bessen, 2020) accompanied by stronger divergence between leaders and laggards in productivity (Andrews et al., 2015) and skills (Song et al., 2019) and a reduction in industrial dynamics (Bessen et al., 2020). The dominant force behind these findings is a virtuous / vicious cycle between firms' vintage choice and their wage offers on the labor market. The choice on the capital good market gets influenced by the skill level within firms. Low skilled firms in comparison to high skilled ones employ workers that learn relatively slowly, take longer to harvest the full productivity of the machine and hence generate less benefits for costly frontier technologies. The capital choice in turn influences wage offers on the labor market, where firms with frontier technologies are able to offer higher wages. In the long run, this interaction results in a stronger segregated firm population with a few frontier firms dominating the market.

A novelty in this paper is the ex-post analysis, which is used to assess determinants and path dependencies on the firm-level. As such, the analysis is in the spirit of the history matters argument emphasized by evolutionary economics (Dosi and Nelson, 2013). More in detail, a simulation time window at the end of the run is fixed, and from this time span the four largest firms are taken called dominant firms. By tracking their path over the whole simulation run and documenting their performance relative to other firm groups such as the average firm, I am able to determine firm characteristics necessary for a successful long-run outcome after the paradigm shift. The main finding concerning the determinants is that the later dominant firms are actually small, but average skilled at the moment of the paradigm shift. In this state they are undervalued, i.e. have a higher potential for output given their productivity. Random events caused by frictions on the labor market allow them to build a relatively high skilled workforce in the following phase of expansion, which in turn triggers the aforementioned virtuous cycle. They continue to expand until they become the largest firms.

The theoretical literature so far has provided several ideas to explain the rise of dominant firms. Some authors emphasis the growing importance of intangible capital as one source of increasing returns to scale (Bessen, 2020; De Ridder, 2019; Aghion et al., 2019). Bessen (2020) argues that scale advantages stemming from high fixed and low marginal costs of software systems lead to increasing productivity dispersion. Similarly, the model by De Ridder (2019) building on Klette and Kortum (2004) relies on different costs structures across firms combined with quality differences stemming from investment in intangible capital. This shift to higher fixed costs allows for scale economics favoring dominant firms. Aghion et al. (2019) assumes that intangible capital increases the ability of firms to spread into new markets enabling the dominance of productive firms. In contrast, within this paper differences in unit costs across 
firms arise endogenously due to uneven adoption rates of new technologies. The leading firms benefit from a virtuous / vicious cycle between labor market and vintage choice that explains the increasing returns after the shift in the technological regime. Combining empirical analysis with a Schumpeterian growth framework Akcigit and Ates (2019a) and Akcigit and Ates (2019b) explain diverging productivity levels and market concentration by a decline in knowledge diffusion. Laggard firms catch-up to frontier firms in their technology with an exogenous probability. A slowdown leads to a stronger technology dispersion and hence higher market concentration. Contrary to them, the slowdown in knowledge diffusion in this study emerges endogenously driven by stronger path dependency as well as strong hysteresis even after the phase of accelerated technological change is over. In addition, this study goes beyond the existing literature by providing a consistent explanation of market concentration that relies on micro level dynamics in explaining the aggregate outcome.

An influential factor during technological change are the skills embodied in the workforce of firms (Pilat, 2005; Dosi et al., 2010b). By employing the EURACE@Unibi model, I am able to include the dynamics on the labor market into the channel from technological change via productivity dispersion to market concentration. Skill differences between firms' labor force stemming from different speeds of learning-on-the-job are an important channel fueling the mechanism relying on increasing returns (Arrow, 1962), but also have predictive power on the long-term success of firms by influencing the vintage choice. This highlights the important role of employees' skills for the opportunities of firms during faster technological change. In this respect, the approach relates to the models by Caselli (1999) and Greenwood and Yorukoglu (1997) who both implement a technological revolution in the context of heterogeneous workers with respect to learning abilities. However, even though these models consider the interaction of technological change and skills in the workforce, such models usually aim to explain inequality dynamics rather than industry dynamics.

The results on the determinants of the largest firms suggest that in times of accelerated technological change small, high skilled firms are successful in the long run, while in times of slow growth firms with a large capital stock are able to dominate the market. This is in line with observations from the empirical literature in the Schumpeterian tradition (Cohen, 2010). While smaller firms tend to lead the change during radical innovations, larger firms are expected to dominate the times of incremental progress along the technological frontier. Different theoretical ideas have been proposed in the literature to explain the failure of large firms during radical innovations, for example destruction of capabilities in the context of technological learning (Breschi et al., 2000), the choice to invest in less risky and less radical R\&D projects (Rosen, 1991) or the inability to anticipate the switch in consumer behavior after a radical innovation (Christensen, 1997). In contrast, I find that the advantage for smaller firms lies in their relatively late investment decision, which generates a productivity gap towards large firms with an old capital stock, in particular during faster technological change.

The model is part of the growing agent-based approach applied to macroeconomics (Dawid 
and Delli Gatti, 2018; Haldane and Turrell, 2019). These models are well equipped to incorporate the role of firm-level heterogeneity in explaining macroeconomic phenomena as they avoid any representative agent or equilibrium notion (Fagiolo and Roventini, 2012; Dosi and Roventini, 2019). Besides the EURACE@Unibi model, the K+S family of models (Dosi et al., 2010a; Dosi et al., 2013; Dosi et al., 2017; Dosi et al., 2018) has a strong focus on endogenous technological change and combines a Schumpeterian with a Keynesian engine. In general, agent-based models are deeply rooted in the evolutionary approach to economics (Dosi and Nelson, 2010) and in recent years have become the main alternative to DSGE models. The lack of empirical relevance has been a crucial argument in this respect, which agent based models are able to overcome (Colander et al., 2008; Kirman, 2010; Stiglitz, 2011). The ability of this model to reproduce recent empirical patterns is remarkable since only the speed of technological change has been varied from the benchmark version (Dawid et al., 2019) and they have not been targeted during the calibration. This further increases the confidence in the results of this study, but also in the EURACE@Unibi model and in the agent-based approach to macroeconomics in general.

A main contribution of this paper to the agent based literature is the detailed ex-post analysis of the firm-level dynamics. By picking the ex-ante "winners" and tracking their trajectory over the whole simulation run, I am able to describe the long-term success of a firm as an emerging property of its own history and through this, enlighten our understanding of the resulting macro phenomena. Here, the micro structure provided by an agent based model is crucial and this way of going from micro to macro is absent in other macroeconomic models. Beyond this, the findings point to several important factors, which agent-based models in general are able to incorporate, in particular the initial conditions at the moment of the shift in the technological regime, heterogeneity at the firm-level, random events on the labor market, positive / negative feedback loops in the decision process and finally, the history of the firm itself, which leads to lock-in effects in different parts of the distribution.

The rest of the paper is organized as follows. Section 2 summarizes the Eurace@Unibi model. In Section 3, I present the experimental setup. In Section 4, we study the results of the simulation experiment. Section 5 concludes with a short discussion. Technical details and robustness checks can be found in Appendix 5.

\section{The model}

The simulation runs are performed with the Eurace@Unibi model. The model employed in my analysis extends the EURACE@Unibi framework. For a detailed description, the reader is refereed to Dawid et al. (2019), in which the developers of the model give a broad overview. This Section provides a short sketch of the most important features for this experiment, whereas further details are documented in Appendix 5. 


\subsection{Overview}

The model consists of the following agents: one capital good producer, populations of consumption good firms and households, a government, banks and one central bank. These agents interact on the labor market, consumption good market, capital good market and the market for credits.

The capital good producer offers vintages with different productivities and prices. The technological frontier - representing the vintage with the highest productivity - develops over time and increases following a stochastic process that reflects the probabilistic nature of innovation. These vintages are purchased by consumption good firms to produce output together with labor in a Leontief production function. Labor and capital are also complementary in the determination of the productivity of the firm. The actual productivity is given by the minimum of the productivity of the employed capital good and the average specific skill of firms' workforce. By the speed of adoption of new vintages, firms determine the speed of technological progress within the given regime. They base their investment decision on a detailed comparison between the offered vintages and their potential expected profits - taking into account the skills of their own workforce and hence the potential of their workers to use the full productivity. Given the focus of this paper on the ICT revolution, vintages are interpreted not only as traditional machines, but also as modern information and communication technologies such as computers, software or algorithms employed in the production process of goods.

Consumption good firms compete on different prices for the budget of households. Prices are set by firms based on simulated purchase interviews with households from which firms make predictions about expected profits. Households use their incomes to consume the offered consumption goods. They decide based on a logit choice model taking into account the different prices.

Households differ with respect to their general as well as their specific skills. On the one hand, general skills are observable by firms and reflect different educational levels reached by the workers. These do not change over time. On the other hand, specific skills determine the actual productivity used in the Leontief production function of consumption good firms. In a learning-on-the-job mechanism, specific skills increase over time as workers use machines with higher productivities. The higher the general skill, the faster the speed of learning. Over time, households become heterogeneous with respect to their specific skills, even in the same general skill group.

The labor market consists of two rounds of a search-and-matching procedure. Consumption good firms post vacancies on the labor market to which households apply excluding the offers below their own reservation wage. Wage offers by firms are based on the expected return from each skill group and on a base wage component which reflects labor market tightness. Because firms can only observe general skills of applicants, they build expectations over specific skills for each general skill group. 


\subsection{Capital good sector}

Technological change The source of technological change is modeled in a simplified way. One monopolistic capital good producer offers a set of vintages ${ }^{4} v=1 \ldots V_{t}$ of different productivities $A^{v}$ to consumption good firms. New vintages are generated by a stochastic process defined by an innovation probability $\mathbb{P}\left[\right.$ Innovation] and an increment $\Delta q_{i n v}$. In case of a successful innovation, a new vintage is added with a productivity increase of $\Delta q_{i n v}$ compared to the previous frontier vintage to the set of offers:

$$
A^{V_{t}}=\left(1+\Delta q_{\text {inv }}\right) \cdot A^{V_{t-1}} .
$$

In this way, the model captures the stochastic nature of technological progress, however within the fixed trajectory determined by $\mathbb{P}($ Innov $)$ and $\Delta q_{\text {inv }}$.

Production and pricing of vintages The production of capital goods is kept stylized. Capital goods are offered with infinite supply and the firm is able to satisfy any demand from the consumption goods sector. For production no input is necessary and hence, labor is absent in this sector. However, to set realistic prices for vintages, it is assumed that the only cost factor is a stylized wage bill. The pricing decision is based on a cost-based price $p_{t}^{\text {cost }}$ and a value-based price $p_{v, t}^{v a l u e}$ :

$$
p_{v, t}=(1-\lambda) \cdot p_{t}^{\text {cost }}+\lambda \cdot p_{v, t}^{\text {value }}
$$

weighted by $\lambda \in[0.1]$, which reflects a bargaining process between the capital good producer and its customer. The cost-based price increases over time and follows the average labor productivity in the economy $B_{t}^{E c o}$ :

$$
p_{t}^{c o s t}=\frac{B_{t}^{E c o}-B_{t-1}^{E c o}}{B_{t}^{E c o}} \cdot p_{t-1}^{c o s t} .
$$

This component is the same across vintages and captures the increasing labor costs for the capital goods producer by assuming wages increase with productivity. For the value-based price component, the capital good producer approximates the productivity gains from its vintage to a representative firm and calculates a discounted productivity

$$
\bar{A}_{t}^{v}=\sum_{s=0}^{S}\left(\frac{1}{1+\rho}\right)^{s} \cdot \min \left[A^{v}, \hat{B}_{t+s}^{E c o}\right]
$$

over a fixed time horizon $S$. The expected average specific skill level $\hat{B}_{t+s}^{E c o}$ is estimated taking the average general skills $B_{\text {gen }}^{E c o}$ and average specific skills $B_{t}^{E c o}$ across consumption good firms. Here, the capital good producer follows the same approach as the consumption good firm in

\footnotetext{
${ }^{4}$ Also terms machine, capital good or technology are used.
} 
their vintage choice (see Eq. 11). Finally, to determine the value-based price for vintage $v$ the capital good producer scales the price per productive unit of the worst vintage $v=1$ from the previous period with the expected productivity for the new vintage $v$

$$
p_{v, t}^{v a l u e}=\bar{A}_{t}^{v} \cdot \frac{p_{t-1}^{1}}{\bar{A}_{t-1}^{1}}
$$

In order to close the model, all profits from this sector are channeled back to households in form of dividend payments.

\subsection{Consumption goods sector}

Production Firms produce horizontally differentiated consumption goods in a Leontief type production function with labor and capital as inputs. The capital stock $K_{i, t}$ consists of different vintages $v$ with different productivities $A^{v}$. Each stock follows

$$
K_{i, t+1}^{v}=(1-\delta) \cdot K_{i, t}^{v}+I_{i, t}^{v}
$$

with investment $I_{i, t}^{v}$ and depreciation rate $\delta$.

Output is given by combining labor $L_{i, t}$ with capital $K_{i, t}$ and the corresponding productivity $\min \left[A^{v}, B_{i, t}\right]$ :

$$
Q_{i, t}=\sum_{v=1}^{V_{t}} \min \left[K_{i, t}^{v}, \max \left[0, L_{i, t}-\sum_{k=v+1}^{V_{t}} K_{i, t}^{k}\right]\right] \cdot \min \left[A^{v}, B_{i, t}\right]
$$

with $A^{v}$ the productivity of vintage $v$ and $B_{i, t}$ the average specific skills within the firm.

To plan the output level, an estimated demand function is calculated once a year based on a detailed analysis. Production instead takes place once a month. In case of expansion, firms get active on the capital as well as labor market. Afterwards, firms deliver their products to the consumption goods market, where they are stored and purchased by households. Firms aim to keep a stock of goods to satisfy demand over the whole month and thus produce above the expected sales by adding a buffer.

Pricing Closely related to the production planning is the pricing behavior. Firms set prices once a year based on simulated purchase surveys with households. Comparing across products, a subset of households sends their willingness to purchase the product of the firm conditional on a given price. Firms choose the profit maximizing option among the considered prices given the resulting demand calculations and their production planning as well as cost structure. ${ }^{5}$

\footnotetext{
${ }^{5}$ More details on the production planning and pricing behavior of firms are documented in Appendix 5. An extensive discussion of the management science approach to model firm behavior can be found in Dawid and Harting (2012).
} 
Consumption market On the consumption market, households use part of their income to purchase products, whereas the rest is saved and stored in bank's deposits. Households consider different prices and decide with a logit choice model on the product by calculating the probability

$$
\mathbb{P}[\text { Household h selects product } i]=\frac{\exp \left(-\gamma^{C} \ln \left(p_{i}, t\right)\right)}{\sum_{i^{\prime}} \exp \left(-\gamma^{C} \ln \left(p_{i}^{\prime}, t\right)\right)}
$$

with parameter $\gamma_{c}$ denoting the price sensitivity of consumers ${ }^{6}$.

Specific skill dynamics Workers $h$ hired by firms differ with respect to their human capital endowment. Each has a fixed and exogenous general skill $b_{h}^{\text {gen }} \in\{1,2,3\}$ reflecting her educational level, with $b_{h}^{\text {gen }}=1$ the lowest and $b_{h}^{\text {gen }}=3$ the highest. In addition, workers are equipped with an endogenously evolving specific skill $b_{h, t}$ reflecting experience on the job. General skills are observable during the hiring process on the labor market, while specific skills are only revealed to firms during production. When workers are employed and operate with machines their specific skill level is adjusted according to:

$$
b_{h, t+1}=b_{h, t}+\chi\left(b_{h}^{g e n}\right) \cdot \max \left[0, A_{i, t}^{v}-b_{h, t}\right]
$$

with $0<\chi\left(b_{h}^{\text {gen }}\right)<1$ the speed of learning for the general skill group $h$ and $A_{i, t}$ the average productivity of the capital stock of employer $i$. The value $\chi\left(b_{h}^{\text {gen }}\right)$ is increasing in general skills, reflecting that learning is faster the higher the educational level of the worker. Additionally, this process takes into account the distance to the frontier, with shorter distances harder to close.

Vintage choice Investment into new vintages happens only when firms are not able to produce their desired output with their current capital stock. Capital demand is estimated by taking the gap in output the firm cannot produce at the moment and is adjusted with firms' average productivity.

To choose between vintages $v$ offered by the capital good producer, firms calculate an effective productivity $\hat{A}_{i, t}^{e f f}(v)$ taking into account their average specific skills $B_{i, t}$ within their workforce over a fixed time horizon $S$ :

$$
\hat{A}_{i, t}^{e f f}(v)=\sum_{s=t}^{S}\left(\frac{1}{1+\rho}\right)^{s} \cdot \min \left[A^{v}, \hat{B}_{i, t+s}\left(A^{v}\right)\right]
$$

with $\rho$ the discount rate. To obtain an estimation for the expected specific skill $\hat{B}_{i, t+s}$ in period

\footnotetext{
${ }^{6}$ Since $\gamma_{c}$ has been found to affect results strongly in other experiments with the Eurace@Unibi model, we provide a variation around the default choice in the sensitivity analysis in Appendix 5.
} 
$t+s$ firms take into account the average general skills $B_{i, t}^{g e n}$ within their workforce:

$$
\hat{B}_{i, t+s}=\hat{B}_{i, t+s-1}+\chi\left(B_{i, t}^{g e n}\right) \cdot \max \left[A^{v}-\hat{B}_{i, t+s-1}, 0\right]
$$

The final decision is made with a logit choice model, for which the expected productivity as well as the price of each vintage is considered to calculate the probability

$$
\mathbb{P}[\text { Firm i selects vintage } v]=\frac{\exp \left(\gamma^{v} \ln \left(\frac{\hat{A}_{i, t}^{e f f}(v)}{p_{t}^{v}}\right)\right)}{\sum_{\bar{v}=1}^{V_{t}} \exp \left(\gamma^{v} \ln \left(\frac{\hat{A}_{i, t}^{e f f}(\bar{v})}{p_{t}^{\bar{v}}}\right)\right)}
$$

Here, it is important to notice that firms choose from a set of vintages and not necessarily pick the frontier technology. If the expected productivity of the best-practice vintage does not offset its higher price, the firm rather invests into a low productive but cheaper capital good. This part is of particular relevance for this experiment since it describes the endogenous diffusion process of vintages.

\subsection{Labor market}

In the process of production planning firms also estimate their labor demand accordingly. Firms fire workers if their workforce is too large and the desired output can be produced with less labor. In this case, low skilled workers are fired first. In addition to this, each month there is a small probability that a worker is fired, capturing job separations the model is silent about. In case a firm needs to hire more workers, a wage offer is posted on the labor market. The wage offer is composed of two parts. The first part is the base wage offer $w_{i, t}^{\text {base }}$, which is driven by the market. It is adjusted upwards by $\varphi$ percentage points, if a firm cannot fill its vacancies and has more than $\bar{v}$ vacancies to fill. The second part is the expected productivity gain for the firm from a worker $h$ with general skill $g$, hence given by the productivity $\min \left[A_{i, t}, \bar{B}_{i, t-1, g}\right]$. Since firms do not observe the specific skill of an applicant, they take their average capital productivity $A_{i, t}$ and the average specific skills $\bar{B}_{i, t-1, g}$ within each general skill group $g$ from their workforce to calculate an expected productivity gain from a new employee. To sum up, firms send out a final wage offer $w_{i, t, g}^{o}$ to each skill group $g$ given by:

$$
w_{i, t, g}^{o}=w_{i, t}^{b a s e} \cdot \min \left[A_{i, t}, \bar{B}_{i, t-1, g}\right]
$$

The wage offer represents a reduced form of a bargaining process, where workers are paid a combination of an outside option $w_{i, t}^{\text {base }}$ and the expected productivity for employer $i$.

Unemployed workers consider a random subset of wage offers for their skill group restricted by their reservation wage $w_{h, t}^{R}$ as a lower bound. The level of the reservation wage is determined first, by their previous wage, and afterwards, in case of an unsuccessful application round on 
the labor market, adjusted downwards by a fraction $\psi$. The lowest bound is the unemployment benefit payment calculated as $u$ percentage of their previous wage. In a next step, unemployed workers send their applications to a set of chosen offers and firms decide on the application accepting high skilled workers with a higher probability. Finally, workers accept the offer generating the highest income. This whole cycle is passed through two times before the labor market closes.

\subsection{Validation}

For our experiment with the Eurace@Unibi model 50 Monte-Carlo batch runs are simulated for each scenario to deal with the stochastic nature of agent based models. I take a standard constellation of parameters and initial values that has been used in other papers before (see Table F1 and F2 in Appendix 5), for example in the description of the benchmark model in Dawid et al. (2019). The model reproduces a large set of empirical stylized facts, which can be found in, e.g., Dawid et al. (2018) and which establish confidence in the model. The list of stylized facts contains several business cycle and labor and credit market properties as well as characteristics of firm distributions. Relevant for this context are the persistent productivity heterogeneity on the firm-level, the lumpiness of investments as well as the right-skewed firm size distribution. In addition, as we will see in the next section the results from this simulation experiment are in accordance with empirical findings connected to the ICT revolution from the late 1970s onward. The ability of the model to reproduce these patterns is particularly remarkable since they have not been targeted in the calibration of the model and the parameter setting has not been adjusted from the default one to match any empirical pattern. 


\section{Experimental setup}

The agenda of my analysis is to explore the process leading to increased market concentration under faster technological change. To address this issue, I compare two different scenarios, the baseline and the paradigm shift. For both, the technological frontier grows at a constant rate with a fixed probability of innovation and a fixed increment for the increase in productivity, until, after a transition phase of 40 years $^{7}$, the two simulation scenarios split up. In the baseline scenario, the speed of technological progress does not change and evolves within the predefined trajectory. In contrast, the paradigm shift scenario experiences a kink in the technological frontier. A shift onto a new trajectory occurs and the frontier grows at a higher speed than before modeled with an increase in the probability of innovation. The two scenarios increasingly deviate from one another with respect to their technological possibilities offered to the consumption good firms. After a certain period the growth of the frontier returns to the baseline growth rate reflecting the fade out of the respective paradigm.

Figure 1 shows the technological frontier. The black solid line represents the baseline scenario. The paradigm shift scenario in red dashed splits from the baseline at day 0 in the middle of the simulation and switches onto a new trajectory. The gray area highlights the period of accelerated technological change.

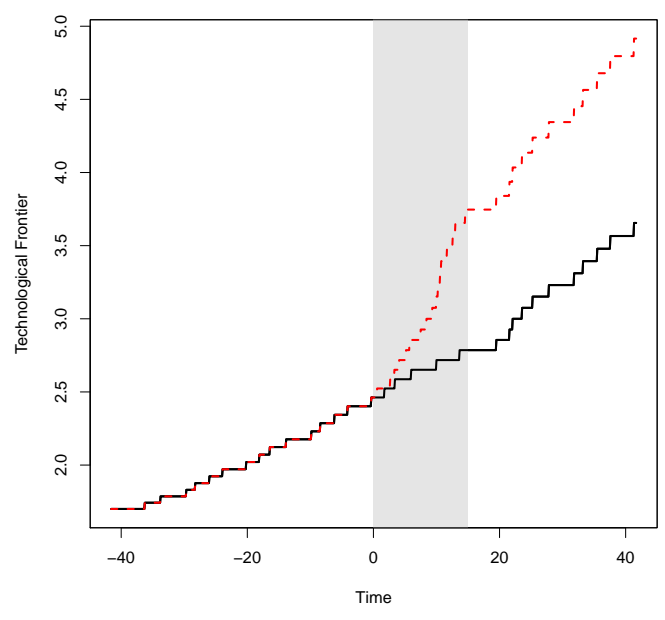

Figure 1. Technological Frontier

Notes: Baseline in black solid; paradigm shift in red dashed. Shaded grey area indicates time of acceleration in technological change. After 15 years, the paradigm shift returns and grows further with the baseline growth rate until the end of the simulation run. Taking the time span from year 0 until the end, the average annual productivity growth is roughly $0.86 \%$ in the baseline and $1.42 \%$ in the paradigm shift scenario.

This simulation experiment aims to model the ICT revolution starting in the late 1970s. The paradigm shift reflects the arrival of a radical invention in a stylized way. The motivating example is the personal computer - a technology used in a very broad set of tasks and which had an impact on many industries. As Malerba et al. (2001) describe, with the invention of the microprocessor the diffusion of the personal computer started and allowed adoption on a large-scale across many information technology-using sectors. This development accelerated technological change, increased productivity of adopting firms, reshaped organizational structures and hence influenced the economy on a large scale, way beyond one narrow application

\footnotetext{
${ }^{7}$ Time units are: 20 iterations equal 1 month, 12 month equal 1 year. Hence, 40 years correspond to roughly 10000 iterations. In all figures, the time unit is years.
} 
or industry (Brynjolfsson and Hitt, 2000; Freeman, 2009). Similarly in this experimental setup, a radical invention increases the speed of technological change and enhances the productivity of new machines offered by the capital good producer after the paradigm shift. Nevertheless, in line with the concept by Dosi (1982) after a certain time the new radical innovation exhausts its potential and the frontier returns to its previous rate of growth. I contrast this scenario with a "World without Computers" - the baseline scenario in which the new technology did not arrive and the frontier keeps growing on the old trajectory. This counterfactual approach allows us to track the changes generated by the paradigm shift.

This way of modeling the ICT revolution heavily relies on the acceleration in productivity growth offered by the new technologies to its adopters. However, as empirical studies showed, computer investment up to the 1990s did not have a positive effect on productivity on the aggregate level. The famous quote by Robert Solow "You can see the computer age everywhere except in the productivity statistics" and the so-called Solow Paradox summarize this issue (Brynjolfsson, 1993). However, according to a large number of studies, the paradox has been resolved. In the survey by Draca et al. (2009), the authors summarize as a main takeaway that ICT accelerated productivity growth on the aggregate level ${ }^{8}$. Additionally, if one turns to the industry or firm-level, from the 1990s on several studies showed that firms and industries adopting ICT undergo stronger productivity growth (see Pilat (2005), Jorgenson et al. (2008), and Draca et al. (2009)). Furthermore, the effect on growth is not only positive, but also gets stronger over time (Kretschmer, 2012), indicating an underlying cumulative process like learning-by-doing.

Complementary skills have been found to be an important part when considering ICT (see Chennells and Van Reenen (2002) and Pilat (2005)). As described in Section 2.3, in the EURACE@Unibi model households are equipped with a general skill level, which is fixed over time and determines the learning ability, and a specific skill level, which endogenously emerges by a learning-on-the-job mechanism. I choose to distinguish households in three different general skill classes with a (fixed) distribution of $25 \%$ of each low and high skilled households and $50 \%$ middle skilled households, roughly matching the OECD average (See Table F1, App. 5).

\section{Results}

The results are split into three parts. The first part describes with a between-scenario analysis the aggregate outcome of our simulation experiment. The second part begins with an in-depth analysis of the paradigm shift scenario. Here, I describe the mechanisms leading to industry concentration and then the determinants of firm characteristics predicting the rise of the later dominating firms. The four largest firms are chosen as the main reference group. I fix the year

\footnotetext{
${ }^{8}$ Based on their review, they claim the Solow paradox was due to an initial small share of ICT in the total stock of capital and the acceleration in aggregate productivity growth in U.S. since 1995 was due to the diffusion of IT technologies. In contrast, they attribute the sluggish productivity growth in the same time period in Europe to poorer performance in sectors relying on ICT (Draca et al., 2009, p. 16).
} 


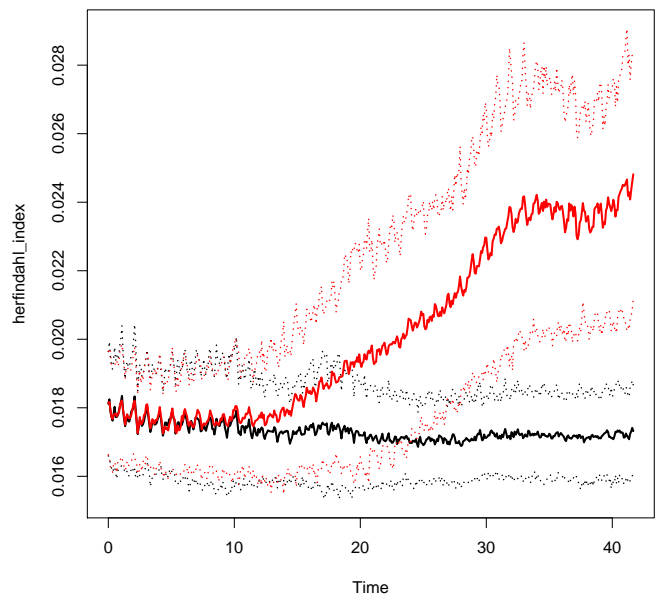

(a)

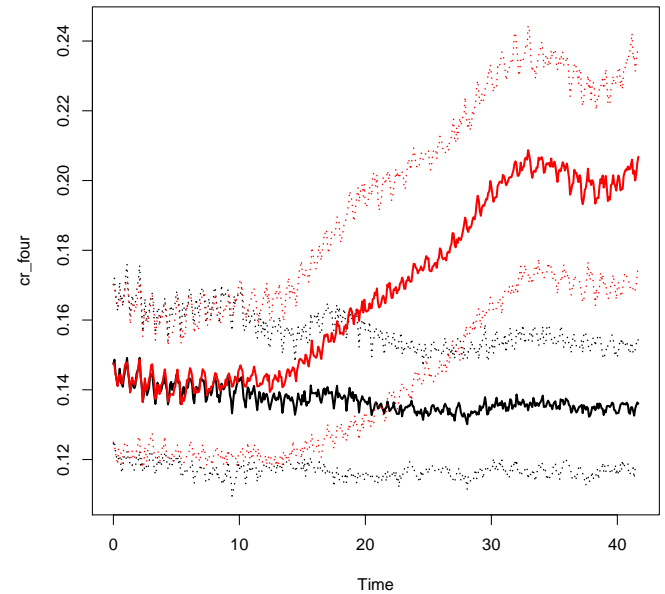

(b)

Figure 2. Concentration measures: Herfindahl index (a) and CR4 (b).

Notes: Baseline in black, paradigm shift in red. Solid lines show the mean over 50 Monte-Carlo simulation runs and dotted lines show plus/minus one between-run standard deviation. Time is measured in years after the paradigm shift scenario. The Herfindahl index is calculated as $\sum_{i} s_{i, t}^{2}$ with $s_{i, t}$ the market share of firm $i$. CR4 displays the market share of the four largest firms as a percentage of the whole market.

35 and take the four largest firms from this time span calling them the dominant firms. Following their path over the whole simulation run, we are able to infer within-firm determinants predicting the rise to the top. The second part concludes with a comparison of the results with the same analysis for the baseline scenario. In the final part, I consider the long-term effects after the frontier returns to the baseline trajectory.

The discussion of the results is organized by stating main insights labeled as Observations and then providing intuition and evidence of the economic mechanisms leading to the conclusions. The analysis begins right after the two scenarios split, hence I abstain from examining the first initial years. By providing strong empirical evidence for the theoretical results, I am able to link them to the current phenomena of industry concentration induced by the ICT revolution. Here, it should be pointed out that this study does not aim to replicate time series quantitatively, but rather to shed light on underlying mechanisms and patterns leading to the observed phenomena. Statistical tests confirm all arguments and robustness checks provide further confidence in the findings, especially with respect to a variation of the parameter choice (Appendix 5).

\subsection{Industry dynamics}

Our discussion begins with the industry dynamics occurring after the paradigm shift, contrasted with the baseline case. The main findings in Observation 1 and Observation 2 are based on Figure 2 and 3, in which the results are based on a comparison of both scenarios with the 


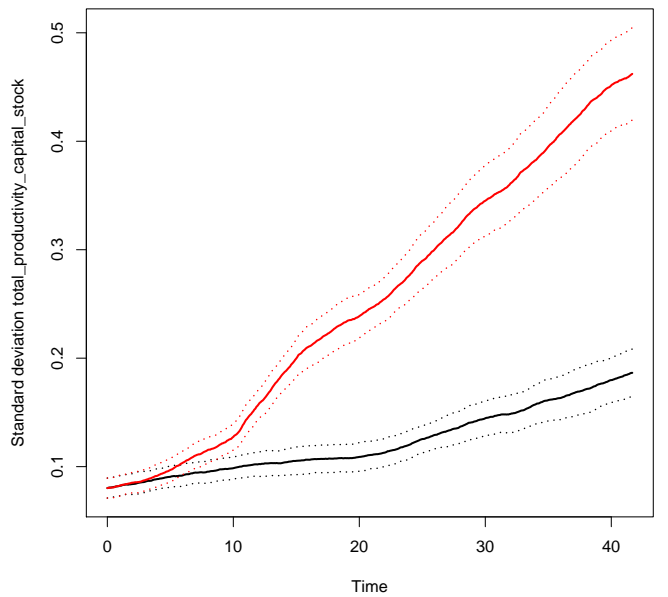

(a)

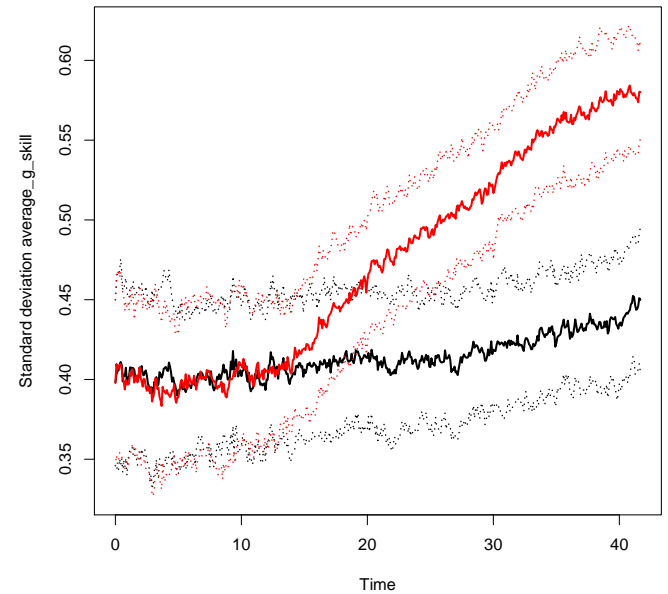

(b)

Figure 3. Standard deviation between firms for productivity of the capital stock (a) and for average general skills (b).

Notes: Baseline in black, paradigm shift in red. Solid lines show the mean over 50 Monte-Carlo simulation runs and dotted lines show plus/minus one between-run standard deviation. Time is measured in years after the paradigm shift scenario.

baseline scenario in black and the paradigm shift in red. Solid lines show the mean over the scenario and dotted lines indicate plus-minus one standard deviation across runs. We infer Observation 3 by estimating transition matrices in Table 1 .

\section{Observation 1 After the paradigm shift, market concentration increases.}

Our first observation is evidenced in Figure $2 a$ and $2 b$. The first panel shows the HerfindahlHirschman index HHI. ${ }^{9}$ Our second measure of market concentration, the CR4 in panel $2 \mathrm{~b}$ refers to the accumulated market shares of the four largest firms and highlights the fat tail of the firm size distribution. In both concentration measures we observe a strong increase roughly 10 years after the paradigm shift. In contrast, market concentration for the baseline scenario stays persistently within its corridor.

Observation 2 After the paradigm shift, capital productivity and average general skills disperse between firms.

The second observation is evidenced in Figure 3a and $3 \mathrm{~b}$. Dispersion of capital productivity is measured by taking the standard deviation of the average capital productivity across firms. For the divergence in skills I consider the standard deviation of average general skills across

\footnotetext{
${ }^{9}$ The HHI is defined as $\sum_{i} s_{i, t}^{2}$ with $s_{i, t}$ the market share of firm $i$. Since this setup employs 80 firms, equal market shares would result in a HHI of 0.0125 .
} 
gap between firms (Barth et al., 2016; Andrews et al., 2016; Berlingieri et al., 2017; Decker et al., 2017), with some linking this to ICT adoption rates (Dunne et al., 2004; Faggio et al., $2010)^{11}$. Related to increasing productivity dispersion is the observed slowdown in technology and knowledge diffusion from frontier to laggard firms (Andrews et al., 2015; Akcigit and Ates, 2019b). Concerning the skill levels of employees, Card et al. (2013) and Song et al. (2019) provide evidence on a segregation in the German and U.S. labor market in form of a clustering of high skilled workers in high productive, high wage firms. For our third observation, Bessen et al. (2020) reports a decline in industry dynamics which is correlated with higher software investment by dominant firms. To conclude this short discussion, our results find strong support in the empirical literature. As pointed out above, the model has not been calibrated nor adjusted to replicate any of these empirical patterns, and its ability to reproduce these establishes further confidence in the model.

\subsection{Path dependencies and determinants after the paradigm shift}

Having documented increasing market concentration as well as diverging productivities and skills across firms after the paradigm shift, this section aims to understand the economic processes driving the two phenomena. For this purpose, I study the decisions on the firm-level over time by picking the four largest firms from one particular year - calling them the dominant firms - and tracking their performance over the whole time horizon. Documenting the history of these four single firms allows us to characterize the path of a successful firm after the paradigm shift. This enables us to first, assess the mechanisms leading to industry concentration, and second, to give a thorough understanding of the underlying process within firms by describing the determinants and the resulting path dependencies.

More in detail, taking an ex-post perspective I choose the year 35 after the paradigm shift and pick the four largest firms in terms of the capital stock in this time period for each run ${ }^{12}$. I call these four firms the dominant firms and follow their rise to the top from the paradigm shift until the end. Comparing them with other firm groups we infer at which part of the firm distribution they are at each point in time and this allows us to make statements about their relative performance. In particular, the average of the current four largest firms at the specified point in time is used as one comparison group. Then, as high tech firms I take the average of the 25 leading firms in terms of productivity of the capital stock. Similarly, as low tech firms I take

\footnotetext{
${ }^{11}$ See also Dosi et al. (2010b) and Syverson (2011). Note that patterns of convergence between firms have been documented for example for China (Yu et al., 2015). The pattern of divergence on the firm-level has been called neodualism (Dosi et al., 2019b) or the great divergence (Berlingieri et al., 2017), and is strongly connected to wage dispersion. In a second paper, I investigate the increasing wage dispersion under technological change and its connection to a polarized firm population.

${ }^{12}$ To be more precise, I take the average size of the capital stock from year 34 to 36 and take the four largest firms in this time span as the dominant firms. The choice of the year 35 is based on the fact that for this year one can see a relatively long time period before but also a short time frame after the arrival at the peak. This facilitates the analysis. Nevertheless, the results are robust to other choices, in particular for the years from 25 to 40 . Further evidence on this is provided in Appendix 5.
} 
the average of the 25 firms with the lowest productivity of the capital stock. The last firm group as a reference for comparison with the dominant firms is the average firm (see Table F3, App. 5 for an overview of the specified firm groups). I plot the dynamics of these groups over time, however, to make differences more visible, in Figure 4 and 5 I take ratios between the average dominant firm and each of the other firm groups. A ratio of 1.0 indicates that the average dominant firm is not significantly different from the average firm in the comparison group. For values above 1.0 one infers that the average dominant firm has a higher value, whereas for values below 1.0 the comparison group exceeds them. All later arguments based on differences between averages of firm groups are supported by Wilcoxon rank-sum tests, which all confirm our statements (see Table F4, App. 5). Figure 4 shows ratios for output, capital productivity, average general skill and average specific skills, whereas Figure 5 shows ratios for base wage offers and prices. The paradigm shift scenario is in the upper and the baseline scenario in the lower panel. Based on these figures, the next observation connects Observation 1 and 2 on the firm-level.

Observation 4 In the paradigm shift scenario, the dominant firms become large due to their increasing superiority in average general skills and capital productivity.

The observation is evidenced in Figure 4a-d. A comparison across scenarios in Figure 4a reveals that the dominant firms are more than four times as large as the average firm after the paradigm shift in terms of output, whereas in the baseline scenario their relative output is roughly twice as large. A more extreme difference is visible for the low tech firms, which are outperformed by a factor of 8 in output. Next, in panels $4 \mathrm{~b}-\mathrm{d}$ we observe that the dominant firms operate at the technological frontier and employ a high skilled labor force in the years before and around year 35. In addition, and in line with Observation 2 differences between the firm groups are more pronounced in the paradigm shift scenario than in the baseline. From this we can infer that the rising dominance of the largest firms is driven by the increasing gap in productivity. The paradigm shift generates stronger productivity differences across firms, and through this initiates a reallocation of market shares from low to high productive firms, which in the long run results in the emergence of a few large firms. 


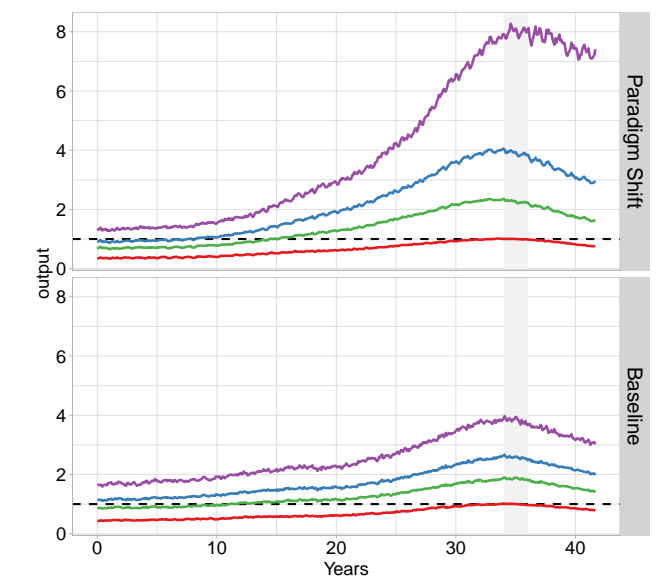

Dominant Firms over - Average - Current Top $4-$ High tech - Low tech

(a)

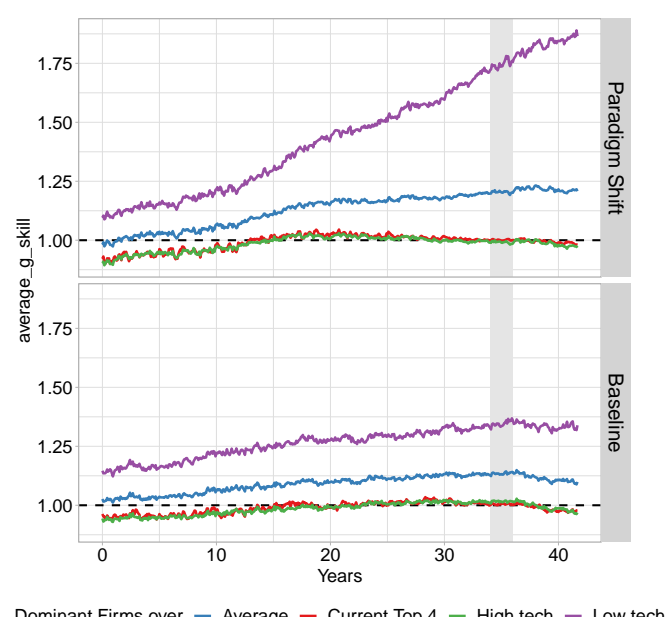

(c)

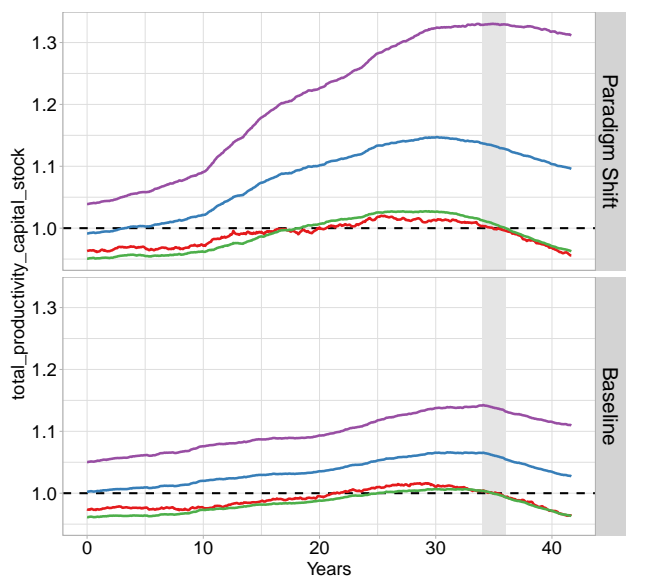

Dominant Firms over - Average - Current Top 4 - High tech - Low tech

(b)

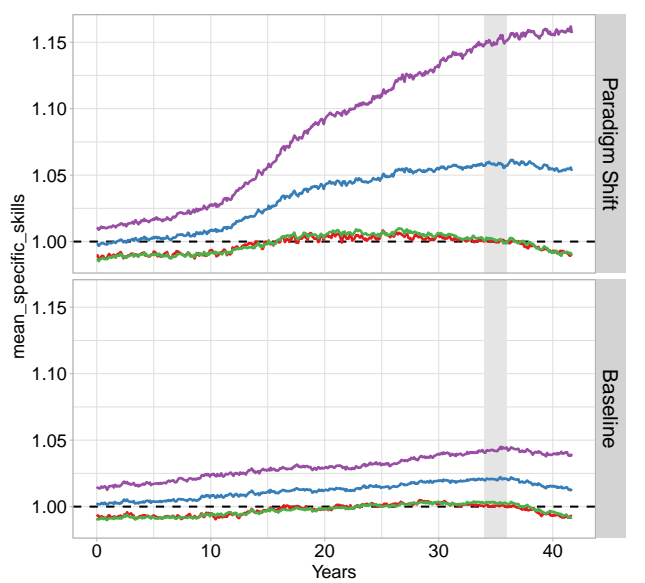

Dominant Firms over - Average - Current Top $4-$ High tech - Low tech

(d)

Figure 4. Ratios for output (a), productivity of the capital stock (b), average general skill (c) and average specific skill (d).

Notes: Relative performance of the dominant firms from the year 35 after the paradigm shift. The dominant firms are defined as the four largest firms in terms of the size of their capital stock plus-minus one year around 35 (shaded area). Time series display ratio of the dominant firms over different firm groups: the average firm (blue), the top 25 of the tech firms (high tech, green), the lowest 25 of tech firms (low tech, purple) and the four largest firms at time point $t$ (current top 4, red). To define the tech groups, firms are ordered according to their average productivity of the capital stock. The black vertical line is at 1.0 to indicate equality between the dominant firms and the other firm groups. All four plots show the paradigm shift scenario in the upper and the baseline scenario in the lower panel. To make differences more visible the variable output has a rescaled $y$-axis by $\log _{2}$. 


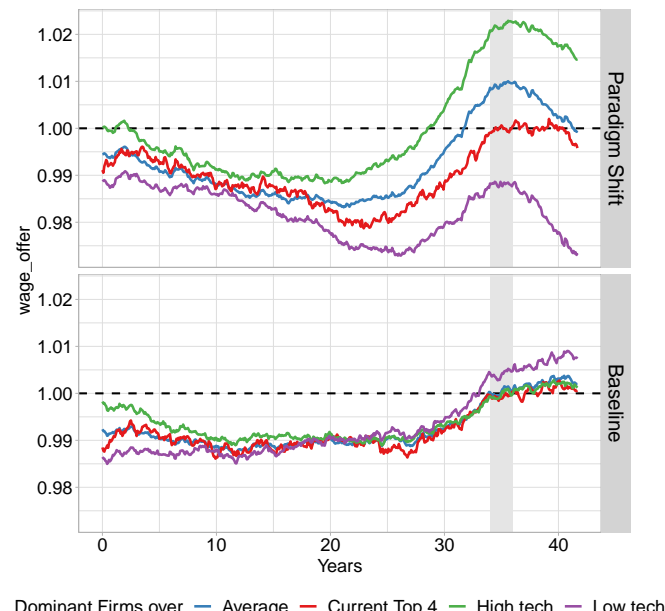

(a)

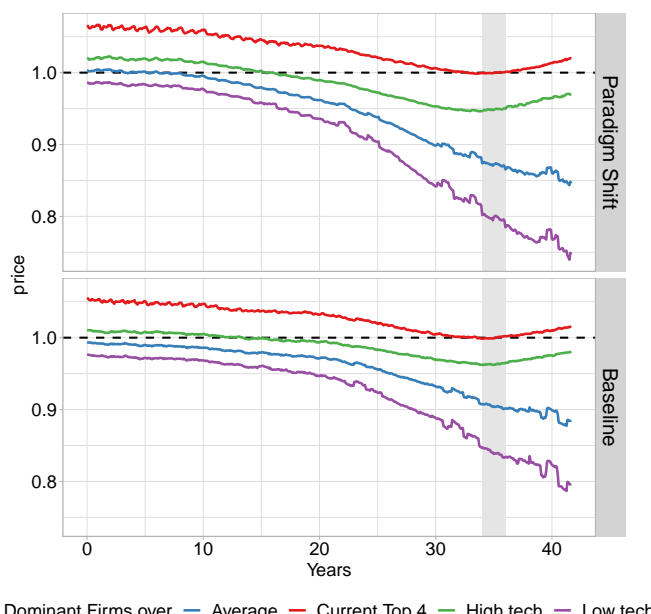

(b)

Figure 5. Ratios for base wage offer (a) and prices (b).

In the following I focus on the paradigm shift scenario and analyze the determinants and path dependencies of the dominant firms. This will further enlighten the process of reallocation of market shares after the paradigm shift and explain the divergence in productivity. Based on Figure 4 and Figure 5 the next observation describes the most important steps a firm has to take to become one of the largest after the paradigm shift.

Observation 5 On their way to the top the dominant firms take the following steps:

Step 1 In the time span right after the paradigm shift, the dominant firms are smaller than the average. The productivity of the capital stock is below average, too. In terms of general skills and specific skills, they are part of the average firm group. This implies that the dominant firms are initially undervalued.

Step 2 In the following years, the dominant firms begin to expand. By chance, they manage to increase the general skills in their workforce during the hiring process on the labor market (years 0-5). By entering a virtuous cycle between vintage choice and success on the labor market, they begin to invest into frontier technologies and over time slowly approach the group of high-tech firms in skills (year 10-15) and in capital productivity and size (year 15-20).

Step 3 They grow further still driven by the virtuous cycle and exceed all other firm groups in terms of capital productivity and skills (year 20-25) until they become the largest four firms (year 35).

The state of the average dominant firm right after the paradigm shift is described in the first step. Considering the relative output in Figure $4 \mathrm{a}$, we observe that shortly after year 0 , the 
dominant firms are significantly smaller than the average firm. In addition, the quality of their capital stock in Figure 4 is below average. With respect to skills (Fig. 4b-d), the later dominant firms are part of the average at the moment of the paradigm shift. This indicates that these firms are undervalued, i.e. their output level could be higher considering their productivity level.

As described in the second step, in the following time span the dominant firms begin to expand and exploit their potential for larger market shares. Before year 10 they reach the average firms in output. Crucially, their productivity and skills have also increased, which implies further potential for output. Indeed, the dominant firms exceed the average firm and catch-up with the most productive firms, the high tech firm group, in terms of skills in year 15 and later in terms of capital productivity in year 20. This explains why they continue to expand their output level such that in year 20 they reach the high tech firms.

During the second step, two observations are crucial for the success of the dominant firms. First, in Figure 5a we observe that the dominant firms have the lowest wage offer. This indicates that they have not been rationed on the labor market, rather, they were able to fill their vacancies without too many rounds in the search and matching procedure. In addition, in year 5 the general skill of their workforce are already above average implying that they were able to hire mostly high skilled workers in this time period. This implies that the frictions on the labor market influence the long-run success of a firm. Second, pushed from this positive shock the dominant firms enter a virtuous cycle. Investment decision and success on the labor market are strongly connected in the model on the firm-level. On the one hand, firms' investment decision depends strongly on the high skilled workforce build up in the previous years. In their decision firms take into account the skills within their current workforce and estimate an expected productivity divided by the price to choose the most profitable option. Indeed, in year 10 the dominant firms have build up a capital stock with an above average productivity. On the other hand, the vintage choice gives feedback to the labor market outcome via the learning mechanism and the expectation formation of firms' on potential applicants. Recall that on the labor market firms compete for heterogeneously skilled workers by posting wage offers. Their wage offer is comprised of a base wage offer reflecting the market tightness and an expected unit of productivity different for each skill group. Since firms cannot observe the specific skills of applicants, they build expectations by taking the average specific skills of their employees with the same average general skills to approximate the productivity component. Since the dominant firms employ the most productive capital goods, their workers learn faster and increase their specific skill level. This in turn influences the expectations of dominant firms about new applicants and they raise their productivity component to attract more high skilled workers. This interaction allows dominant firms to prosper and is the main reason why these firms become the largest in the long-run. Furthermore, it also explains the higher firm heterogeneity after the paradigm shift. Those firms with high skilled workers benefit from a fast learning labor force and invest in a high productive capital stock, while their competitors increasingly lag behind.

The third step describes the path of the dominant firms from a high productive one to the 
top as a continuation of the virtuous cycle. As one can see in Figure $4 \mathrm{~b}$, after year 20 the dominant firms exceed all other firm groups and employ the most productive capital stock, which decreases their unit costs and allows them to set the lowest prices (Fig. 5b) to finally become the largest firms in year 35 .

Even though the dominant firms in the baseline scenario are not as large and for all variables differences between firm groups are less pronounced, I contrast the findings of the paradigm shift scenario with the same analysis for the benchmark one in the next observation.

Observation 6 In comparison to the paradigm shift scenario, the dominant firms in the baseline scenario are larger than the average firm already 35 years before their peak.

The lower panel in Figure 4a displays the relative output in the baseline scenario. Here, the average dominant firm is significantly larger than the average firm over the whole time span (see Table F4, App. 5). This stands in sharp contrast to the determinant in the paradigm shift scenario, in which the dominant firms are smaller than the average in the beginning. Nevertheless, the mechanism leading to the rise of a firm to the top in the baseline and paradigm shift scenario have overlapping elements. Being large from the beginning onwards, the later largest firms hire by coincidence (see the wage offer in Fig. 5a) mostly high skilled workers (Fig. 4c). They slowly become part of the frontier firms in terms of skills (year 15) and - via the same virtuous cycle supported by a favorable, but stochastic outcome at the labor market - also in terms of capital productivity (year 25). They expand their output steadily until they become the largest firms (year 35).

The main insight from this comparison is that in the baseline scenario size matters acts as the main barrier for the rise of a firm to the top, which is quite distinct from the determinants of the dominant firms after the paradigm shift. But what is driving this shift in path dependencies? What is the advantage of small over larger firms after the paradigm shift? Smaller firms that become larger over time have the advantage that their capital stock is more up-to-date, i.e. more productive compared to a firm that is large already and only invests to replace depreciated capital. While the initially small firms build up a capital stock that is comprised of mostly new technologies from the frontier, the relatively large firms employ a capital stock composed of old technologies. However, this advantage for smaller firms is absent in the baseline scenario, since here a high productive capital stock of yesterday is still among the most productive ones tomorrow.

As before, we conclude this section by comparing our findings with empirical studies related to the ICT paradigm. With the result in Observation 3 we are able to connect the observed phenomena of industry concentration (Autor et al., 2020) with productivity and skill dispersion across firms (Andrews et al., 2016; Song et al., 2019). Autor et al. (2020) shows that more concentrated industries experienced a stronger reduction in the diffusion of new technologies. Related, Bessen (2020) argues that IT systems induce a reallocation of market shares due to a 
widening gap in productivity levels between firms in the same industry. His empirical findings support this hypothesis, however, remain silent about a precise channel. The author points out that learning might play a crucial role in explaining the diverging success in operating IT systems (Bessen, 2015; Bessen, 2020). In line with this, Observation 5 explains in a similar vein how the dispersion in productivity gets manifested by a reinforcing cycle between decisions on the labor and capital goods market. Thereby, it builds on accumulating process of learning-onthe-job as a crucial driver in generating heterogeneous increasing returns and manifesting path dependencies. While some workers are able to implement the new systems faster and generate higher productivity gains for their firms, others lag behind and their employers hesitate to invest into new and costly technologies. This generates the dispersion in productivity levels in the short term, but additionally influences the expectations and future decisions of firms reinforcing the dominance of the leaders in the long term. Through this channel, the result highlights a potential connection between the slowdown in technology diffusion (Andrews et al., 2015; Akcigit and Ates, 2019b) and the intensifying segregation on the labor market (Card et al., 2013; Song et al., 2019; Criscuolo et al., 2020). During the diffusion of the computer, this might have lead to uneven adoption rates across firms, increased the productivity gap between frontier and laggard firms and in turn reallocated market shares to a few dominating firms.

In addition, the determinants from Observation 4 and 5 predicting the rise of the dominant firms in the model are in accordance with empirical findings showing that skill-intensive firms are more likely and successful in adopting ICT (Pilat, 2005; Dosi et al., 2010b). For example, Doms et al. (1997) find that firms adopting new technologies employ more high skilled workers before as well as after their investment. Some studies address the importance of human capital in the process of technology diffusion by analyzing wages within firms as a signal for a skilled workforce. An example is Chennells and Van Reenen (1997), which find that higher wages influence technical change rather than vice versa. Considering country-level data, Caselli and Coleman (2001) find that higher adoption rates of the computer are associated with higher levels of human capital within the country. Finally, in their management survey approach, Bloom et al. (2012) document that more sophisticated management practices within firms are relevant for the early and successful adoption of new technologies. Overall, these studies support the result on the important role of high skilled workers within a firm during a phase of accelerated technological change.

\subsection{Lock-in effect after the paradigm shift}

We recall that in the paradigm shift scenario, the technology becomes mature after some time and the innovation rate switches back to the old level (Fig. 1). With the slowdown in the growth rate of the technological frontier, what happens to market concentration and the firm population? To answer this in our final observation, we consider in Figure 6 the annual growth rate of firm productivity. 
Observation 7 With the slowdown of the growth rate of the technological frontier in the paradigm shift scenario, the annual firm productivity growth decreases back to the values in the baseline scenario in the long run. The increased market concentration and the stronger divergence across firms stay at the higher levels.

In Figure 6, we see that - consistent with the way we modify the technological frontier - the paradigm shift increases productivity growth at the firm-level. After the phase of accelerated technological change and a peak around year 15, the growth rate slows down again until it reaches the baseline value at the end of the simulation run. However, this return is not happening for the other dynamics visible in the last time periods of Figure 2 and 3. After the initial increase in concentration and divergence, no return to the previous levels occurs, but a stagnation at above baseline values. The lower mobility of firms across the distribution (Tab. 1) further indicates that the economy is locked in a state of high concentration. The phase of accelerated technological change had a persistent effect on the economy.

The driver of this lock-in effect (or hysteresis) is the process of accumulative learning. As we pointed out before, via the virtuous cycle this mechanism generates the rise of the dominant firms to the top. At the same time, it acts as a vicious cycle and prevents laggard firms from catching up. Firms left behind do not develop the same specific skill levels in the workforce, which lowers their actual productivity. In addition, this also reduces their relative wage offers and they are not able to compete for high skilled labor at the labor market. This exclusion from technological knowledge embodied in part of the workforce decreases their incentive to invest in frontier technologies and they fall further behind. ${ }^{13}$ Even though the growth of the technological frontier slows down, the distance towards their competitors became too large and they are locked in a polarized state.

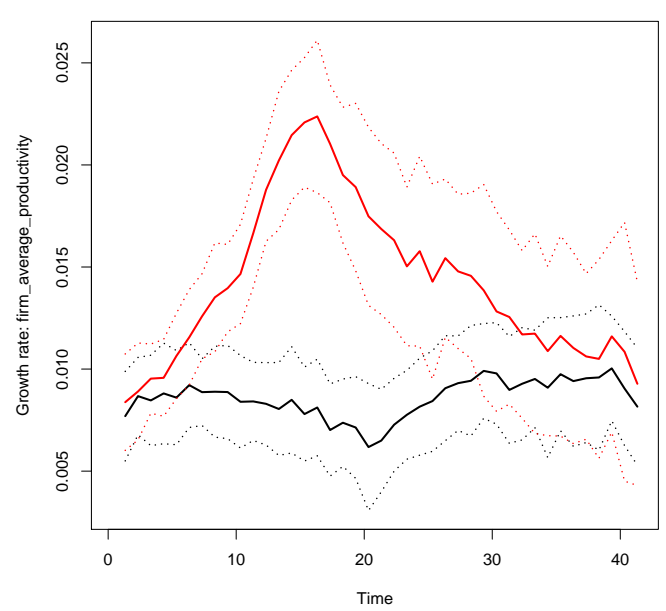

Figure 6. Annual average growth rate for firm productivity.

Notes: Baseline in black, paradigm shift in red. Solid lines show the mean over 50 Monte-Carlo simulation runs and dotted lines show plus/minus one between-run standard deviation. Time is measured in years after the paradigm shift scenario.

Finally, note that our results are inline with recent empirical findings of a slowdown in the aggregate productivity growth (Andrews et al., 2016). Rather, our findings suggest that a phase of accelerated technological change - as

\footnotetext{
${ }^{13}$ This can be seen for example in the relative performance of low tech firm group in Figure 4. Over time the gap towards the other firm groups increases.
} 
it happened for example in the late 1990s in the US (Draca et al., 2009) - is enough to cause a persistent effect on the underlying firm population and the allocation of market shares. ${ }^{14}$

\section{Discussion and concluding remarks}

This paper takes a closer look at the firm-level mechanisms and determinants that can explain the rise of large dominant firms after an acceleration in technological change. On the macro level, the simulation results show the generic emergence of a few large firms after a paradigm shift in the technological regime. Here, the heterogeneity at the firm-level becomes crucial for deriving the result. As the main driver we identify a stronger divergence of the firm population in terms of capital productivity and skills. Some firms enter a virtuous cycle between their investment decision on the capital good market and their outcome on the labor market. At the core of this process of dynamic increasing returns lies the accumulation of technological knowledge in form of a learning on-the-job mechanism as well as the complementarity between labor and capital in determining the actual productivity of the firm. While a high skilled workforce incentivizes to invest in high productive capital goods, investment at the frontier in turn enables faster growth of skills within the workforce. Two clubs of firms emerge with the market leaders operating at the technological frontier and laggard firms falling further behind. Even though the technological regime returns to its previous growth rate after some time, the phase of accelerated technological change has a persistent effect and leaves the economy in a state of higher market concentration and stronger divergence. With a lower mobility of firms across the distribution, the laggards are left behind unable to overcome the generated gap.

The rich micro structure of the model enables us to track the largest firms and to point out explicitly the determinants leading to their rise. Exploring the determinants, we found that decisions and success of firms are highly dependent across time pointing to strong path dependencies, which in turn are conditional on the type of the technological regime - in line with the history matters argument emphasized by evolutionary economics (Arthur, 1989; Castaldi and Dosi, 2003; Dosi and Nelson, 2013). In addition, the analysis highlights the ability of agent-based models to study firm performances at different time scales. In contrast to other macroeconomic frameworks, we are able to document the transition of a firm to the top over a long-time span and to differ between initial conditions as well as determinants on the way. The results show that the largest firms in the long run are initially smaller than the average at the moment of the paradigm shift. During this small time window, a fortunate event on the labor market enables their future success by providing them with (mostly) high skilled workers. By entering the aforementioned virtuous cycle they become the most productive firms and in the long run generate the highest market shares. This mechanism relies on market frictions at the labor market, which in the model stem from partially coordinated interactions of the economic

\footnotetext{
${ }^{14}$ Nevertheless, it is not clear whether the productivity slowdown is actually related to ICT intensity and the discussion about its determinants is ongoing (Syverson, 2017).
} 
agents based on the explicit market protocols, here the search and matching procedure.

The approach in this theoretical paper is motivated by an ongoing debate around empirical observations of rising industry concentration (Van Reenen, 2018; Gutierrez and Philippon, 2020). To relate to this discussion, the main example for technological development in mind is the wave of ICT starting in the 1980s, which has been taken as one potential source for the rising dominance of so-called superstar firms (Bessen, 2020). I contribute to this discussion by providing a detailed story consistent with several recent trends connected to the diffusion of ICT. Transferring the results of this paper to the context of ICT, the setup takes as a starting point the reasonable assumption that increased productivity enhancements for firms have been made possible due to the diffusion of the computer. However, heterogeneous adoption rates influenced by skill intensities within firms generate an increasing gap between firms. As a result, segregation on the labor market and clustering of high skilled workers in a few firms further increased productivity differences. In the long run, the growing dispersion in productivity allowed a few firms to emerge and to become "superstars". Interestingly, the ex-post analysis suggests that these firms are not necessarily large in the beginning. In fact, the findings suggest that with the acceleration in technological change smaller firms were able to cope best with the new environment and become the industry leaders in the long-run. Finally, even after the slowdown of productivity growth, the firm population is locked in a state of higher divergence and the paradigm shift shaped the economy persistently.

\section{References}

Aghion, Philippe, Antonin Bergeaud, Timo Boppart, Peter J. Klenow, and Huiyu Li (2019). "A Theory of Falling Growth and Rising Rents". Federal Reserve Bank of San Francisco Working Paper 2019-11. Akcigit, Ufuk and Sina T. Ates (2019a). "Ten Facts on Declining Business Dynamism and Lessons From Endogenous Growth Theory". American Economic Journal: Macroeconomics 1.1, pp. 1-13.

- (2019b). "What Happend To U.S. Business Dynamism?” NBER Working Paper No. 25756.

Andrews, By Dan, Chiara Criscuolo, and Peter N Gal (2015). "Frontier Firms, Technology Diffusion and Public Policy: Micro Evidence From OECD Countries". OECD Productivity Working Papers 2.

Andrews, Dan, Chiara Criscuolo, and Peter N. Gal (2016). "The Best versus the Rest: the Global Productivity Slowdown, Divergence across Firms and the Role of Public Policy". OECD Productivity Working Papers 5.

Arrow, Kenneth J. (1962). "The Economic Learning Implications of by Doing”. The Review of Economic Studies 29.3, pp. 155-173.

Arthur, W. Brian (1989). "Competing Technologies, Increasing Returns, and Lock-In by Historical Events". The Economic Journal 99.394, pp. 116-131.

Autor, David, David Dorn, Lawrence F Katz, Christina Patterson, and John Van Reenen (2020). "The Fall of the Labor Share and the Rise of Superstar Firms". Quarterly Journal of Economics.

Bajgar, Matej, G. Berlingieri, Sara Calligaris, Chiara Criscuolo, and Jonathan Timmis (2019). "Industry Concentration in Europe and North America". OECD Productivity Working Papers 18. 
Barth, Erling, Alex Bryson, James C. Davis, and Richard Freeman (2016). "It's Where You Work: Increases in the Dispersion of Earnings across Establishments and Individuals in the United States". Journal of Labor Economics 34.S2, S67-S97.

Berlingieri, G., P. Blanchenay, and C. Criscuolo (2017). "The great divergence(s)". OECD Policy Paper 39 , p. 75.

Bessen, James (2015). "Information Technology and Learning On-The-Job". Working Paper.

- (2020). "Industry Concentration and Information Technology". The Journal of Law and Economics 63.

Bessen, James, Joowon Kim, Erich Denk, and Cesare Righi (2020). "Declining Industrial Disruption". BU Law School Working Paper.

Bloom, Nicholas, Raffaella Sadun, and John Van Reenen (2012). "Americans do IT better: US multinationals and the productivity miracle". American Economic Review 102.1, pp. 167-201.

Böhl, Gregor, Sander van der Hoog, and Philipp Harting (2014). ETACE Virtual Appliance.

Breschi, Stefano, Franco Malerba, and Luigi Orsenigo (2000). "Technological regimes and schumpeterian patterns of innovation". Economic Journal 110.463, pp. 388-410.

Bresnahan, Timothy (2010). General purpose technologies. 1st ed. Vol. 2. 1. Elsevier B.V., pp. 761-791.

- (2019). "Technological change in ICT in light of ideas first learned about the machine tool industry". Industrial and Corporate Change 28.2, pp. 331-349.

Brynjolfsson, Erik (1993). “The Productivity Paradox of Information Technology”. Business Computing 36.12.

Brynjolfsson, Erik and Lorin M Hitt (2000). "Beyond Computation: Information Technology". Journal of Economic Perspectives 14.4, pp. 23-48.

Brynjolfsson, Erik and Kristina McElheran (2016). "The rapid adoption of data-driven decision-making”. American Economic Review 106.5, pp. 133-139.

Caiani, Alessandro (2017). "Innovation Dynamics and Industry Structure Under Different Technological Spaces". Italian Economic Journal 3.3, pp. 307-341.

Card, David, Jörg Heining, and Patrick Kline (2013). "Workplace Heterogeneity and the Rise of West German Wage Inequality”. The Quarterly Journal of Economics 128.3, pp. 967-1015.

Caselli, Francesco (1999). "Technological Revolutions". American Economic Association 89.1, pp. 78102.

Caselli, Francesco and John Wilbur Coleman (2001). "Cross-Country Technology Diffusion: The Case of Computers". American Economic Review 91.2, pp. 328-335.

Castaldi, Carolina and Giovanni Dosi (2003). "The grip of history and the scope for novelty: Some results and open questions on path dependence in economic processes". LEM Working Paper Series 02.

Chennells, Lucy and John Van Reenen (1997). "Technical Change and Earnings in British Establishments". Economica 64.256, pp. 587-604.

- (2002). "The Effects of Technical Change on Skills, Wages and Employment: A Survey of the Microeconometric Evidence”. In: Productivity, Inequality and the Digital Economy. Ed. by Y. L'Horty, N. Greenan, and J. Mairesse. Cambridge, MA: MIT Press, pp. 175-225.

Christensen, Clayton M (1997). The Innovator's Dilemma: When New Technologies Cause Great Firms to Fail. Harvard Business School Press. 
Cohen, Wesley M. (2010). Fifty years of empirical studies of innovative activity and performance. Vol. 1. 1 C. Elsevier B.V., pp. 129-213.

Colander, By David, Peter Howitt, Alan Kirman, Axel Leijonhufvud, and Perry Mehrling (2008). "Beyond DSGE Models : Toward an Empirically Based Macroeconomics". American Economic Association 98.2, pp. 15-20.

Criscuolo, Chiara, Alexander Hijzen, Cyrille Schwellnus, Erling Barth, Wen-hao Chen, Richard Fabling, Priscilla Fialho, Balazs Stadler, Richard Upward, and Wouter Zwysen (2020). "Workforce composition, productivity and pay: the role of firms in wage inequality". OECD Economics Department Working Papers No. 16031603.

Dawid, H. and S. Gemkow (2014). "How do social networks contribute to wage inequality? Insights from an agent-based analysis". Industrial and Corporate Change 23.5, pp. 1171-1200.

Dawid, H., P. Harting, and M. Neugart (2014). "Economic convergence: Policy implications from a heterogeneous agent model". Journal of Economic Dynamics and Control 44, pp. 54-80.

- (2018). "Cohesion policy and inequality dynamics: Insights from a heterogeneous agents macroeconomic model". Journal of Economic Behavior and Organization 150, pp. 220-255.

Dawid, Herbert (2006). "Agent-based Models of Innovation and Technological Change". Handbook of Computational Economics Volume 2 88, pp. 1235-1272.

Dawid, Herbert and D Delli Gatti (2018). "Agent-Based Macroeconomics”. In: Handbook of Computational Economics, Vol. 4 - Heterogeneous Agent Models. Ed. by Cars Hommes and Blake LeBaron. Elsevier, pp. 63-156.

Dawid, Herbert and Philipp Harting (2012). "Capturing firm behavior in agent- based models of industry evolution and macroeconomic dynamics". In: Applied Evolutionary Economics, Behavior and Organizations. Ed. by Guido Bünstorf. Edward-Elgar, pp. 103-130.

Dawid, Herbert, Philipp Harting, Sander Van der Hoog, and Michael Neugart (2019). "Macroeconomics with Heterogeneous Agent Models: Fostering Transparency, Reproducibility and Replication". Journal of Evolutionary Economics 29, pp. 467-538.

De Ridder, Maarten (2019). "Market Power and Innovation in the Intangible Economy". LSE Research Online Documents on Economics.

Deaton, Angus (1991). "Saving and Liquidity". Econometrica 59.5, pp. 1221-1248.

Decker, Ryan A., John Haltiwanger, Ron S. Jarmin, and Javier Miranda (2017). "Declining dynamism, allocative efficiency, and the productivity slowdown". American Economic Review 107.5, pp. 322 326.

Deissenberg, Christophe, Sander van der Hoog, and Herbert Dawid (2008). "EURACE: A massively parallel agent-based model of the European economy". Applied Mathematics and Computation 204.2, pp. 541-552.

Doms, Mark, Timothy Dunne, and Kenneth R. Troske (1997). "Workers, wages, and technology". The Quarterly Journal of Economics February.

Dosi, G, M C Pereira, A Roventini, and M E Virgillito (2018). "Causes and consequences of hysteresis : aggregate demand, productivity, and employment". Industrial and Corporate Change 27.6, pp. 1015-1044. 
Dosi, Giovanni (1982). "Technological paradigms and technological trajectories". Research Policy 11, pp. $147-162$.

- (1988). "Sources, Procedures, and Microeconomic Effects of Innovation". Journal of Economic Literature 26.3, pp. 1120-1171.

- (2007). "Statistical regularities in the evolution of industries: a guide through some evidence and challenges for the theory". In: Perspectives on Innovation. Ed. by F. Malerba and S. Brusoni. Cambridge University Press.

Dosi, Giovanni, Giorgio Fagiolo, Mauro Napoletano, and Andrea Roventini (2013). "Income distribution, credit and fiscal policies in an agent-based Keynesian model". Journal of Economic Behavior and Organization 37, pp. 1598-1625.

Dosi, Giovanni, Giorgio Fagiolo, and Andrea Roventini (2010a). "Schumpeter meeting Keynes: A policyfriendly model of endogenous growth and business cycles". Journal of Economic Dynamics \& Control 34, pp. 1748-1767.

Dosi, Giovanni, Marco Grazzi, Daniele Moschella, Gary Pisano, and Federico Tamagni (2019a). "Longterm firm growth: an empirical analysis of US manufacturers 1959-2015”. Industrial and Corporate Change, pp. 1-24.

Dosi, Giovanni, Dario Guarascio, Andrea Ricci, and Maria Enrica Virgillito (2019b). "Neodualism in the Italian business firms: training, organizational capabilities, and productivity distributions". Small Business Economics 2016.

Dosi, Giovanni, Sébastien Lechevalier, and Angelo Secchi (2010b). "Introduction: Interfirm heterogeneitynature, sources and consequences for industrial dynamics". Industrial and Corporate Change 19.6, pp. 1867-1890.

Dosi, Giovanni, Orietta Marsili, Luigi Orsenigo, and Roberta Salvatore (1995). "Learning, Market Selection and the Evolution of Industrial Structures”. Small Business Economics 7, pp. 411-436.

Dosi, Giovanni, Mauro Napoletano, Andrea Roventini, and Tania Treibich (2017). "Micro and macro policies in the Keynes + Schumpeter evolutionary models". Journal of Evolutionary Economics, pp. 63-90.

Dosi, Giovanni and Richard Nelson (2013). "The Evolution of Technologies: an Assessment of the StateOf-The-Art". Eurasian Business Review 3.1, pp. 3-46.

Dosi, Giovanni and Richard R. Nelson (2010). Technical change and industrial dynamics as evolutionary processes. Vol. 1. 1 C. Elsevier B.V., pp. 51-127.

Dosi, Giovanni and Andrea Roventini (2019). "More is different ... and complex! The case for agentbased macroeconomics". Journal of Evolutionary Economics 29, pp. 1-37.

Dosi, Giovanni, Andrea Roventini, and Emanuele Russo (2019c). "Endogenous growth and global divergence in a multi- country agent-based model". Journal of Economic Dynamics \& Control.

Draca, Mirko, Raffaella Sadun, and John Van Reenen (2009). "Productivity and ICTs: A review of the evidence". In: The Oxford Handbook of Information and Communication Technologies. Ed. by R. Mansell, C. Avgerou, Danny Quah, and R. Silverstone. Oxford University Press, pp. 1-65.

Dunne, Timothy, Lucia Foster, John Haltiwanger, and Kenneth R. Troske (2004). "Wage and Productivity Dispersion in United States Manufacturing: The Role of Computer Investment". Journal of Labor Economics 22.2, pp. 397-429. 
Faggio, Giulia, Kjell G. Salvanes, and John van Reenen (2010). "The evolution of inequality in productivity and wages: Panel data evidence". Industrial and Corporate Change 19.6, pp. 1919-1951.

Fagiolo, Giorgio and Andrea Roventini (2012). "Macroeconomic Policy in DSGE and Agent-Based Models". Revue de l'OFCE 124.5, pp. 67-116.

Freeman, Chris (2009). "The ICT paradigm". In: The Oxford Handbook of Information and Communication Technologies. Ed. by Chrisanthi Avgerou, Robin Mansell, Danny Quah, and Roger Silverstone. Oxford University Press, pp. 1-27.

Freeman, Christopher and Francisco Louca (2001). As Time Goes by: From the Industrial Revolutions to the Information Revolution. Oxford University Press: Oxford.

Freeman, Christopher and Carlota Perez (1988). "Structural Crises Of Adjustment, Business Cycles and Investment Behaviour". In: Technical Change and Economic Theory, pp. 38-66.

Greenwood, Jeremy and Mehmet Yorukoglu (1997). "1974”. Carnegie-Rochester Conference Series on Public Policy 46.

Gutierrez, German and Thomas Philippon (2020). "Some Facts about Dominant Firms". NBER Working Paper 27985.

Haldane, Andrew G. and Arthur E. Turrell (2019). "Drawing on different disciplines: macroeconomic agent-based models". Journal of Evolutionary Economics 29.1, pp. 39-66.

Harting, Philipp (2020). "Macroeconomic Stabilization and Long-Term Growth: the Role of Policy Design". Macroeconomic Dynamics, pp. 1-46.

Hötte, Kerstin (2020a). "How to accelerate green technology diffusion? Directed technological change in the presence of coevolving absorptive capacity". Energy Economics 85.

- (2020b). "The economics of transition pathways: A proposed taxonomy and a policy experiment". Environmental Innovation and Societal Transitions 36.May, pp. 94-113.

- (2021). "Skill transferability and the stability of transition pathways - A learning-based explanation for patterns of diffusion”. Journal of Evolutionary Economics Forthcoming.

Jorgenson, Dale W., Mun S. Ho, and Kevin J. Stiroh (2008). "A retrospective look at the United States productivity growth resurgence". Journal of Economic Perspectives 22.1, pp. 3-24.

Kirman, Alan (2010). "The Economic Crisis is a Crisis for Economic Theory”. CESifo Economic Studies 56.

Klette, Tor Jakob and Samuel Kortum (2004). "Innovating firms and aggregate innovation”. Journal of Political Economy 112.5, pp. 986-1018.

Kretschmer, Tobias (2012). "Information and Communication Technologies and Productivity Growth: A Survey of the Literature". OECD Digital Economy Papers 195.

Malerba, Franco, Richard Nelson, Luigi Orsenigo, and Sidney Winter (2001). "Competition and industrial policies in a 'history friendly' model of the evolution of the computer industry". International Journal of Industrial Organization 19.5, pp. 635-664.

Nelson, Richard R (1981). "Research on Productivity Growth and Productivity Differences: Dead Ends and New Departures". Journal of Economic Literature 19.3, pp. 1029-1064.

Nelson, Richard R and Sidney G Winter (1982). "The Schumpeterian Tradeoff Revisited”. The American Economic Review 72.1, pp. 114-132.

Nuvolari, Alessandro (2020). "The Revolution in Historical Perspective". GROWINPRO Working Paper. 
OECD (2019). Education at a Glance 2019, pp. 1-520.

- (2020). Adult education level (indicator).

Perez, Carlota (1985). "Microelectronics, long waves and world structural change: New perspectives for developing countries". World Development 13.3, pp. 441-463.

- (2010). "Technological revolutions and techno-economic paradigms". Cambridge Journal of Economics 34.1, pp. 185-202.

Pilat, Dirk (2005). "The ICT Productivity Paradox: Insights from Micro Data". OECD Economic Studies 2004.1, pp. 37-65.

R Core Team (2016). R: A Language and Environment for Statistical Computing.

Rosen, Richard J (1991). "Research and Development with Asymmetric Firm Sizes". The RAND Journal of Economics 22.3, pp. 411-429.

Silverberg, Gerald and Doris Lehnert (1993). "Long waves and 'evolutionary chaos' in a simple Schumpeterian model of embodied technical change". Structural Change and Economic Dynamics 4.1, pp. 9-37.

Song, Jae, David J Price, Fatih Guvenen, Nicholas Bloom, and Till von Wachter (2019). "Firming Up Inequality". The Quarterly Journal of Economics 134.1, p. 93.

Stiglitz, Joseph E. (2011). "Rethinking macroeconomics: What failed, and to how repair it". Journal of the European Economic Association 9.4, pp. 591-645.

Syverson, Chad (2011). “What determines productivity?” Journal of Economic Literature 49.2, pp. 326365.

- (2017). "Challenges to Mismeasurement Explanations for the US Productivity Slowdown". Journal of Economic Perspectives 31.2, pp. 165-186.

Van Der Hoog, Sander and Herbert Dawid (2019). "Bubbles, Crashes, and the Financial Cycle: the Impact of Banking Regulation on Deep Recessions". Macroeconomic Dynamics 23.3, pp. 12051246.

Van Reenen, John (2018). "Increasing Differences between firms: Market Power and the Macro-Economy". Jackson Hole Conference 2018.

Winter, Sidney G. (1984). "Schumpeterian competition in alternative technological regimes". Journal of Economic Behavior and Organization 5.3-4, pp. 287-320.

Yu, Xiaodan, Giovanni Dosi, Jiasu Lei, and Alessandro Nuvolari (2015). "Institutional change and productivity growth in China's manufacturing: The microeconomics of knowledge accumulation and "creative restructuring"”. Industrial and Corporate Change 24.3, pp. 565-602. 


\section{Appendices}

\section{Appendix A: Code and data availability}

The code of the Eurace@Unibi model has not been changed with respect to the benchmark model. The data from the simulation experiments is available upon request. The data has been processed and analyzed with the software package R, see R Core Team, 2016.

\section{Appendix B: Parametrization and initialization}

Table F1 gives the number of agents as well as the distribution and different speeds of learning for the three skill groups. Table F2 documents the most important parameters.

\section{Appendix C: Statistical tests}

The results in Sections 4.2 rely on differences between the average dominant firm and different comparison groups (see Table F3 for a recap of the definitions of the considered firm groups). To confirm statistical significance of the observations, in Table F4 I document the results of two-sided Wilcoxon signed-rank tests, the non-parametric counterpart of the $t$-test for paired samples. The average dominant firm is compared with the average of the specified comparison group over 50 Monte-Carlo runs for different years and different variables. The statements in Observation 4 and Observation 5 are all confirmed by the statistical analysis.

\section{Appendix D: Robustness checks}

\section{Appendix D1: Sensitivity analysis for parameter $\gamma_{c}$}

As a robustness check for the results from Section 4.1 and 4.2 the consumer sensitivity $\gamma_{c}$ is varied around the default value of 17.0. Households use this parameter in their logit choice model to decide on products with different prices. A higher (lower) value indicates stronger (weaker) price sensitivity and hence stronger (weaker) competition for market shares among firms, which makes it a crucial parameter in the analysis of market concentration and firm competition. I replicate the main results for $\gamma_{c}$ in a range of 15.0 to 19.0. For each integer value in-between, 30 Monte-Carlo runs are conducted.

Results from Section 4.1 Observation 1 and Observation 2 are the main results in this Section. To confirm the validity under different $\gamma_{c}$ values, statistical tests are performed to see the difference between the paradigm shift and the baseline scenario. I use a Mann-Whitney U-test, the non-parametric counterpart of the $t$-test for unpaired samples, with the equality of the two scenarios as Null-hypothesis $H_{0}$. Indicators are the variables from Figure 2 and 3 in year 35, in particular the $\mathrm{CR} 4$ and the HHI for market concentration and the standard deviation of capital 
productivity as well as of average general skills across firms to infer the segregation in the firm population.

In Table F5 ratios between scenarios and $p$-values for the three hypothesis are reported. All $p$-values are highly significant and the findings are stable for the entire range of the parameter values. Quantitatively, one observes that the differences between the scenarios in terms of industry concentration get stronger with a higher $\gamma_{c}$. This is reasonable, since $\gamma_{c}$ determines the competitiveness across firms on the consumption goods market and as such has a strong impact on the allocation of market shares.

Results from Section 4.2 Next, the main results from these Sections covering the determinants of the later dominant firms are summarized in Observation 4 and Observation 5. To see the effects of a variation in $\gamma_{c}$, I show the plots for variables output (Fig. F2) and productivity (Fig. F3).

Even though the results are more complex than for the previous sensitivity analysis, we can confirm the patterns from the default setting. The main observation from this robustness check is that an increase (decrease) in $\gamma_{c}$ accelerates (slows down) the rise of the dominant firm and hence the described process happens later (earlier). This can be seen for example when considering the relative size of the dominant firms in the years after the paradigm shift. For higher (lower) values of $\gamma_{c}$, the catch up in size towards the average firm group happens later (earlier). Similarly, for higher (lower) values of $\gamma_{c}$ the dominant firms exceed the average and reach the high tech firms in terms of productivity in later (earlier) periods. The stronger (weaker) competition does not affect the results qualitatively, but rather shifts the timing of the events.

\section{Appendix D2: Sensitivity analysis for the year 35}

In Section 4.2, the analysis of the dominant firms is based on the year 35. As the choice of the precise year is somewhat arbitrary, in Figure F1 the same dynamics for output, capital productivity, average general skills and the wage offer are shown - now based on the dominant firms in year 25 . Here, the year 25 serves as a lower bound because market concentration in the paradigm shift scenario has increased and surpassed the baseline value significantly around this period (see Fig. 2), from which one can conclude that dominant firms begin to emerge and are different than the large firms in the baseline scenario. The results stay qualitatively the same, however, as a further robustness check the same statistical tests as in Table F4 is documented in Table F6. For this case, only the paradigm shift scenario is documented. The statistical tests confirm the patterns described in Observation 4 and 5. 


\section{Appendix E: Further details on the model}

In what follows, I continue the description from Section 2 of the Eurace@Unibi model in more detail. Again the reader is referred to Dawid et al. (2019) since the description in this paper cannot cover the whole model and is still leaving away parts irrelevant to this experiment. Especially the financial sector is documented very briefly, but can be found in Dawid et al. (2019, Sec. 3.4) in full length.

\section{Time}

The smallest time unit in the model is one day with 5 days being one week, 20 days one month and 240 days one year. Decisions by agents in the model are triggered on a weekly, monthly or yearly basis. All figures in this paper show values on a monthly basis. This is due to the fact that the production cycle of firms is executed in this interval. Furthermore, labor and capital market also open once a month. However, most of firms and households decision are a-synchronized to avoid overshooting effects stemming from simultaneous decisions. For example, firms start the production cycle or households go shopping on different days in the month.

\section{Consumption good sector}

Quantity choice Firms serve the consumption good market sending their products to a mall once a month, where their goods are stored and purchased by households on a weekly basis. Before firms start their production, they reevaluate their quantity choice aiming to keep their stock in the mall at a certain level. The critical inventory stock $Y_{i, t}$ is the sum of the expected demand $\hat{D}_{i, t}$ and a buffer depending on the variance of the demand distribution (described in paragraph Pricing). In case the firm plans to produce to serve the mall and needs to fill up its inventory stock, an output analysis is conducted to calculate its capital and labor demand. To approximate the desired output, the firm calculates its feasible output employing its full capital stock. If the desired output exceeds the feasible one, the firm gets active on the capital goods market and invests into new vintages (see paragraph Vintage choice in Section 2.3). Afterwards, the workforce is expanded on the labor market or workers are dismissed depending on the size of the labor force and firms' labor demand (see Section 2.4).

Pricing Prices are set once a year with the aim to maximize expected profits taking into account sales and costs. For a set of prices the firm conducts four steps of analysis projecting into the future over a fixed time horizon $S$. First, in the market analysis the firm estimates a demand curve. For this, an overall market analysis extrapolating the current market trend into the future is combined with an individual-based analysis evaluating potential market shares. Here, households are asked about their willingness to purchase the product for different prices as well as different competing products in so-called simulated purchase interviews. In a second stage, the firm sets up a preliminary production plan making use of the estimated demand curve as 
well as its inventory policy. Third, after having an output plan for each price, a cost analysis is conducted for which the firm takes into account possible fixed costs stemming from capital investment and labor costs as well as its updated payment account. Finally, the firm estimates for each price the expected profits discounting by $\rho$ and obtains its profit-maximizing price.

Bankruptcy Two cases of bankruptcy are possible: first, the firm cannot pay its outstanding financial commitments like taxes and interest payments (illiquidity) or second, firms' equity becomes negative after the production cycle (insolvency). In either case, if a firm goes bankrupt, all employees are fired and the firm stays inactive for one year. The capital stock is not destroyed and becomes active again together with the firm. Some part of firms' debt is written off and results in bad debts for the credit giving banks.

\section{Households}

Income Households receive income from four potential sources: in form of wages paid by their employee, unemployment benefits from the government, dividends from firms depending on the shares they hold and interest payments from the bank on their deposits. Income taxes are paid on a monthly basis to the government.

Consumption and savings Based on a well-established heuristic from the literature (Deaton, 1991), each month households determine their consumption budget $C_{h, t}$ by calculating

$$
C_{h, t}=I_{h, t}^{\text {Mean }}+\kappa\left(W_{h, t}+\phi I_{h, t}^{\text {Mean }}\right)
$$

with $W_{h, t}$ its total wealth and $I_{h, t}^{M e a n}$ its average income of the last $T$ periods. The income to wealth ratio is given by parameter $\phi$. The consumption budget gets spend over the month on a weekly basis on products offered in the mall, whereas the accumulated wealth is split among a risk-free bank deposit and a risky financial asset in form of index shares of firms.

\section{Remaining sectors}

Banks Banks store the money of households and supply credits to firms. They pay interest payments to households and taxes to the government. In turn they receive dividend payouts on credits granted to firms. A central bank holds banks reserves and lends them money on which interest payments are exchanged.

Government The government collects taxes from households, firms and banks, which are channeled back into the economy via unemployment benefits. Hence, its role is exclusively distributional. 


\section{Appendix F: Tables \& figures}

Table F1. Distribution of agents.

\begin{tabular}{llc}
\hline Agents & Name & Value \\
\hline & Households & 1600 \\
Consumption good firms & 80 \\
Capital good producer & 1 \\
Banks & 20 \\
\hline
\end{tabular}

Skill Distribution

\begin{tabular}{llcc}
$b_{\text {gen }}$ & Label & Percentage of Households & Adaption Speed Specific Skills \\
\hline 1 & Low & $25 \%$ & 0.0125 \\
2 & Middle & $50 \%$ & 0.024765 \\
3 & High & $25 \%$ & 0.03703 \\
\hline
\end{tabular}

Notes: The number of agents is taken from the standard setup, for example in Dawid et al. (2019). I choose three skill groups - different in their speed of learning - and distribute households among these groups matching roughly the OECD average of $25-45-30$ for below upper-secondary, upper-secondary and tertiary educational levels in 2010 (OECD, 2019; OECD, 2020). Additionally, there is one central bank and one government. This paper uses the one-region version of the model. 
Table F2. Values of selected parameters.

\begin{tabular}{|c|c|c|}
\hline Parameter & Description & Value \\
\hline \multirow[t]{3}{*}{$\mathbb{P}[$ Innovation $]$} & Probability of innovation & \\
\hline & Baseline scenario & $3.3 \%$ \\
\hline & Paradigm Shift scenario & $10 \%$ \\
\hline$\Delta q_{i n v}$ & Technological progress (increment) & 0.025 \\
\hline$p_{0}^{v}$ & Initial capital price & 20 \\
\hline$\lambda$ & Bargaining power of the capital goods producer & 0.5 \\
\hline$\delta$ & Capital depreciation rate & 0.01 \\
\hline$\gamma^{v}$ & Logit parameter for vintage choice & 30.0 \\
\hline$u$ & Wage replacement rate & 0.70 \\
\hline$\varphi$ & Firm base wage update & 0.01 \\
\hline$\psi$ & Reservation wage update & 0.01 \\
\hline$v$ & Number of unfilled vacancies triggering wage update & 2 \\
\hline$\alpha_{D}$ & Number of applications per day & 3 \\
\hline$\alpha_{T}$ & Total number of applications per month & 5 \\
\hline$\gamma^{c}$ & Intensity of consumer choice & 17 \\
\hline$\chi$ & Service level for the expected demand & 0.8 \\
\hline$\rho$ & Discount rate & 0.02 \\
\hline$S$ & Firm time horizon in months & 24 \\
\hline$\Phi$ & Target wealth/income ratio & 16.67 \\
\hline$\kappa$ & Adjustment wealth/income ratio & 0.01 \\
\hline$r^{c}$ & ECB interest rate & 0.05 \\
\hline
\end{tabular}

Notes: The probability of innovation is the only parameter varied between the two scenarios. The technological frontier develops with an expected annual growth rate of roughly $1.2 \%$ in the baseline and with $5.8 \%$ in the paradigm shift scenario. The parameter choices are based on Dawid et al. (2019) and are within the range of previously chosen ones.

Table F3. Firm groups.

\begin{tabular}{lc}
\hline Name & Description \\
\hline $\begin{array}{l}\text { Dominant } \\
\text { Current Top } 4\end{array}$ & four largest firms in terms of capital stock averaged over years $34-36$ \\
High Tech & four largest firms in terms of capital stock in year $t$ \\
Low Tech & highest 25 firms in productivity of capital stock in year $t$ \\
Average & lowest 25 firms in productivity of capital stock in year $t$ \\
\hline
\end{tabular}


Table F4. Wilcoxon tests for Observation 4 and Observation 5.

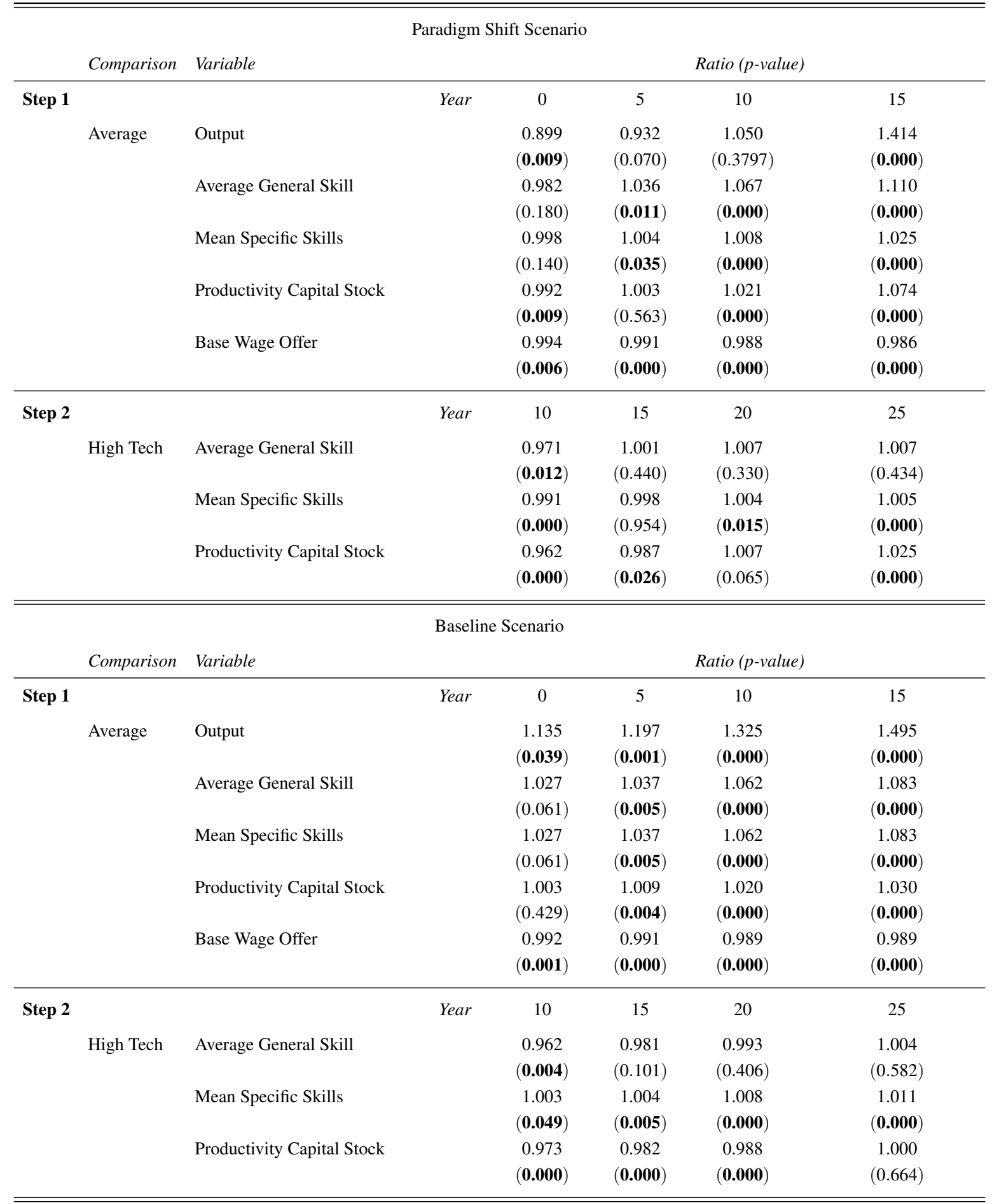

Notes: Values are ratios for dominant firms over comparison group (second row) for variable (third row). If the ratio is below 1.0, the dominant firms are smaller, and vice versa otherwise. The values in brackets show $p$-values for a two-sided Wilcoxon signed-rank test between firm group means within scenarios, with $H_{0}$ : no difference between firm groups, hence $H_{0}: \mu_{d o m}=\mu_{c o m p}$ with 50 observations (MC runs). $p$-values below 5\% are highlighted in bold. The upper part shows the paradigm shift scenario, the lower the baseline scenario. 
Table F5. Mann-Whitney U-test for Observation 1 and Observation 2 varying parameter $\gamma_{c}$.

\begin{tabular}{lccccc}
\hline & \multicolumn{5}{c}{ Ratios (p-values) for different $\gamma_{c}$} \\
& 15.0 & 16.0 & 17.0 & 18.0 & 19.0 \\
\hline Observation 1 & & & & & \\
CR4 & 1.188 & 1.317 & 1.550 & 1.488 & 1.386 \\
& $(\mathbf{0 . 0 0 1})$ & $(\mathbf{0 . 0 0 0})$ & $(\mathbf{0 . 0 0 0})$ & $(\mathbf{0 . 0 0 0})$ & $(\mathbf{0 . 0 0 0})$ \\
HHI & 1.091 & 1.241 & 1.424 & 1.404 & 1.379 \\
& $(\mathbf{0 . 0 0 2})$ & $(\mathbf{0 . 0 0 0})$ & $(\mathbf{0 . 0 0 0})$ & $(\mathbf{0 . 0 0 0})$ & $(\mathbf{0 . 0 0 0})$ \\
Observation 2 & & & & & \\
Std capital productivity & 2.536 & 2.506 & 2.455 & 2.460 & 2.094 \\
& $(\mathbf{0 . 0 0 0})$ & $(\mathbf{0 . 0 0 0})$ & $(\mathbf{0 . 0 0 0})$ & $(\mathbf{0 . 0 0 0})$ & $(\mathbf{0 . 0 0 0})$ \\
Std average general skill & 1.312 & 1.284 & 1.310 & 1.296 & 1.230 \\
& $(\mathbf{0 . 0 0 0})$ & $(\mathbf{0 . 0 0 0})$ & $(\mathbf{0 . 0 0 0})$ & $(\mathbf{0 . 0 0 0})$ & $(\mathbf{0 . 0 0 0})$ \\
\hline
\end{tabular}

Notes: Ratios for specified variable from year 35 with paradigm shift scenario over baseline scenario varying $\gamma_{c}$ from 15.0 to 19.0. $p$-values in brackets for Mann-Whitney U-test between scenarios with $H_{0}$ : no difference between scenarios. $p$-values below 5\% are highlighted in bold. The tests are based on 30 Monte-Carlo runs for each scenario and parameter value of $\gamma_{c}$.

Table F6. Wilcoxon tests for Observation 4 with dominant firms from year 25.

\begin{tabular}{|c|c|c|c|c|c|c|}
\hline \multicolumn{7}{|c|}{ Paradigm Shift scenario } \\
\hline & Comparison & Variable & & & Ratio & \\
\hline \multirow[t]{5}{*}{ Step 1} & & & Year & 0 & 5 & 10 \\
\hline & Average & Output & & $\begin{array}{c}0.901 \\
(\mathbf{0 . 0 3 5})\end{array}$ & $\begin{array}{c}1.086 \\
(0.359)\end{array}$ & $\begin{array}{c}1.392 \\
(\mathbf{0 . 0 0 0})\end{array}$ \\
\hline & & Average General Skill & & $\begin{array}{c}1.004 \\
(0.847)\end{array}$ & $\begin{array}{c}1.061 \\
(\mathbf{0 . 0 0 0})\end{array}$ & $\begin{array}{c}1.094 \\
(\mathbf{0 . 0 0 0})\end{array}$ \\
\hline & & Productivity Capital Stock & & $\begin{array}{c}1.002 \\
(0.203)\end{array}$ & $\begin{array}{c}1.025 \\
(\mathbf{0 . 0 0 0})\end{array}$ & $\begin{array}{c}1.056 \\
(\mathbf{0 . 0 0 0})\end{array}$ \\
\hline & & Wage Offer & & $\begin{array}{c}0.992 \\
(\mathbf{0 . 0 0 0})\end{array}$ & $\begin{array}{c}0.991 \\
(\mathbf{0 . 0 0 0})\end{array}$ & $\begin{array}{c}0.986 \\
(\mathbf{0 . 0 0 0})\end{array}$ \\
\hline \multirow[t]{3}{*}{ Step 2} & & & Year & 10 & 15 & 20 \\
\hline & High Tech & Average General Skill & & $\begin{array}{c}0.995 \\
(0.463)\end{array}$ & $\begin{array}{c}1.014 \\
(\mathbf{0 . 0 1 7})\end{array}$ & $\begin{array}{c}1.002 \\
(0.493)\end{array}$ \\
\hline & & Productivity Capital Stock & & $\begin{array}{c}0.995 \\
(0.127)\end{array}$ & $\begin{array}{c}1.026 \\
(\mathbf{0 . 0 0 0})\end{array}$ & $\begin{array}{c}1.028 \\
(\mathbf{0 . 0 0 0})\end{array}$ \\
\hline
\end{tabular}

Notes: The basis of this Table are the dominant firms from year 25 in the paradigm shift scenario. Values are ratios for dominant firms over comparison group (second row) for variable (third row). If the ratio is below 1.0, the dominant firms are smaller, and vice versa otherwise. The values in brackets show $p$-values for a two-sided Wilcoxon signed-rank test between firm group means within scenarios, with $H_{0}$ : no difference between firm groups, hence $H_{0}: \mu_{d o m}=\mu_{\text {comp }}$ with 50 observations (MC runs). $p$-values below $5 \%$ are highlighted in bold. 


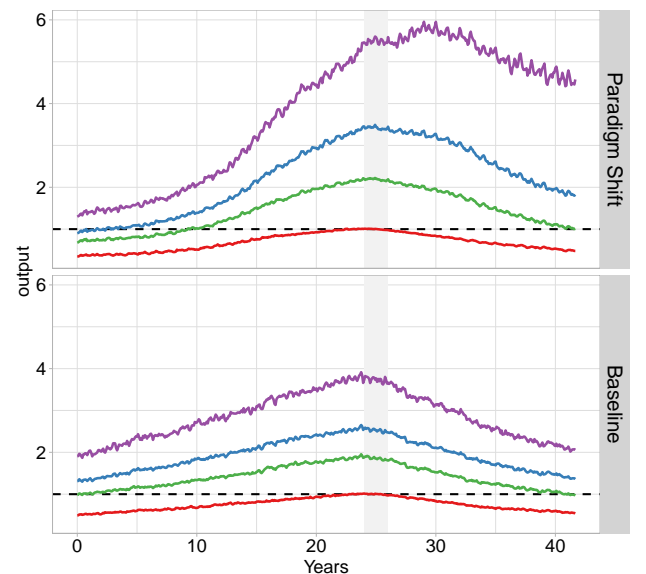

Dominant Firms over - Average - Current Top $4-$ High tech - Low tech

(a)

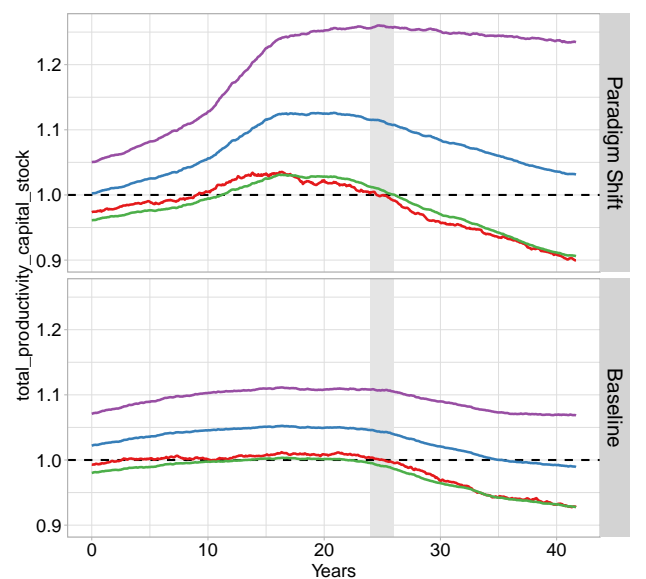

Dominant Firms over - Average - Current Top $4-$ High tech - Low tech

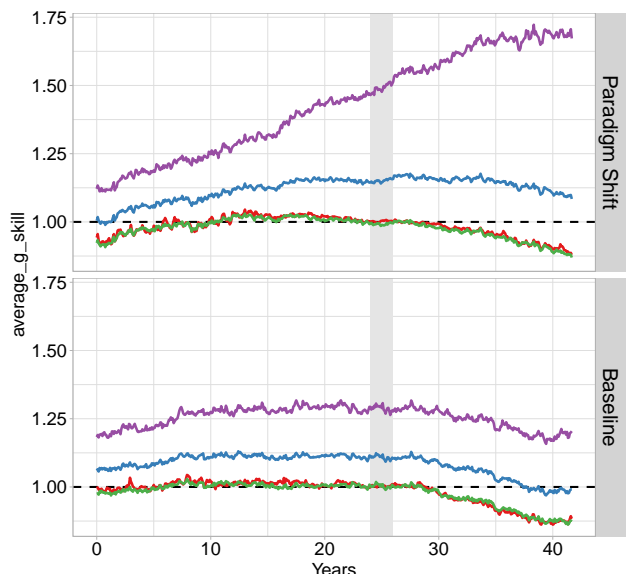

Dominant Firms over - Average - Current Top 4 - High tech - Low tech

(b)

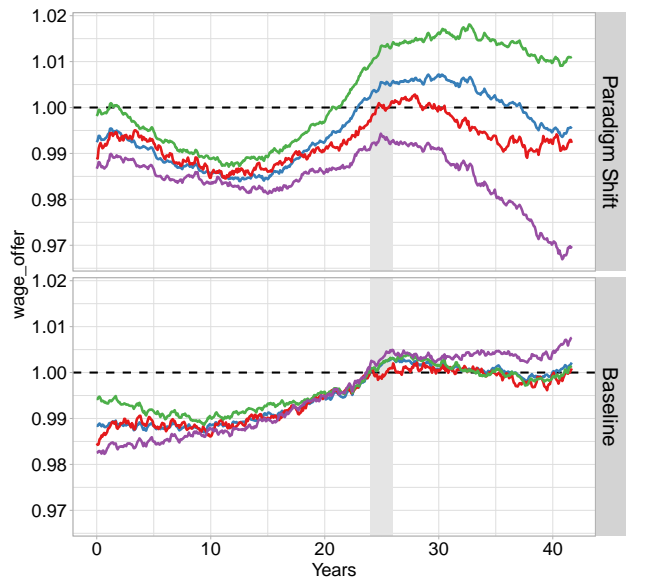

Dominant Firms over - Average - Current Top $4-$ High tech - Low tech

(d)

Figure F1. Relative performance of the dominant firms from the year 25 after the paradigm shift in: output (a), average general skill (b), productivity of the capital stock (c), and wage offer (d). Definitions correspond to Figure 4. 


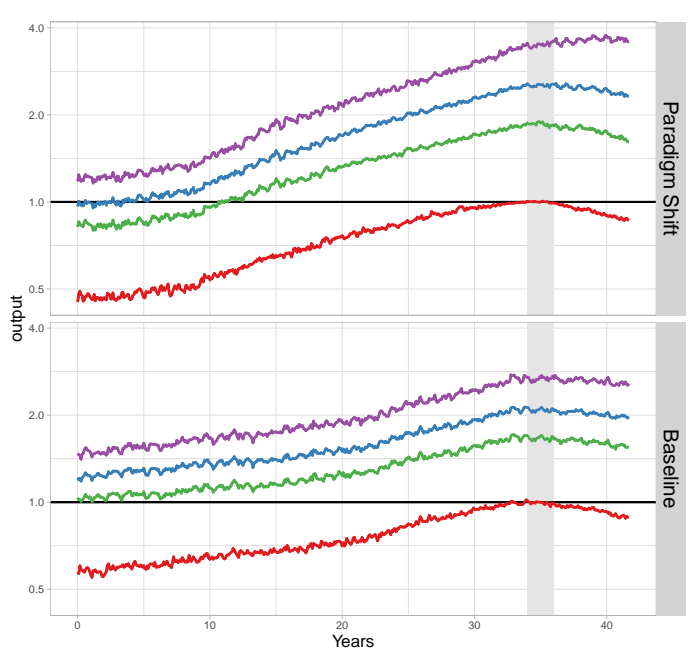

Dominant Firms over - Average - Current Top $4-$ High Tech - Low Tech

(a) $\gamma_{c}=15$

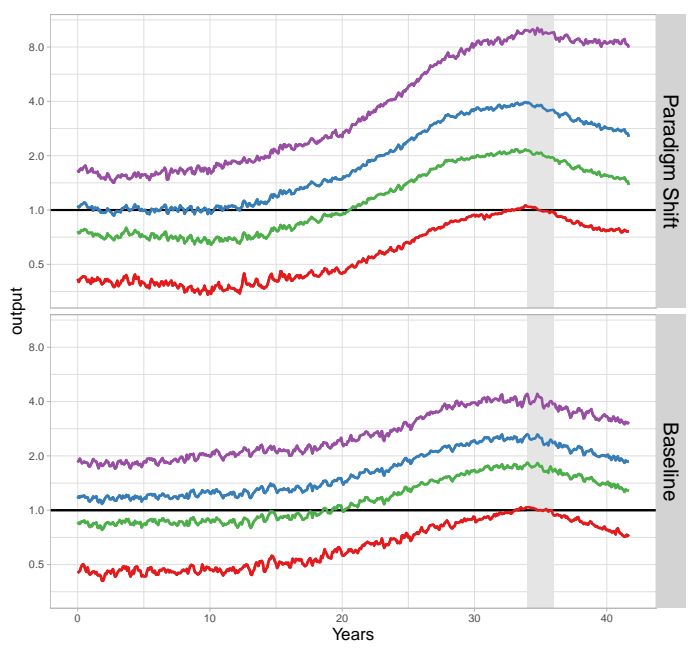

Dominant Firms over - Average - Current Top $4-$ High Tech - Low Tech

(c) $\gamma_{c}=18$

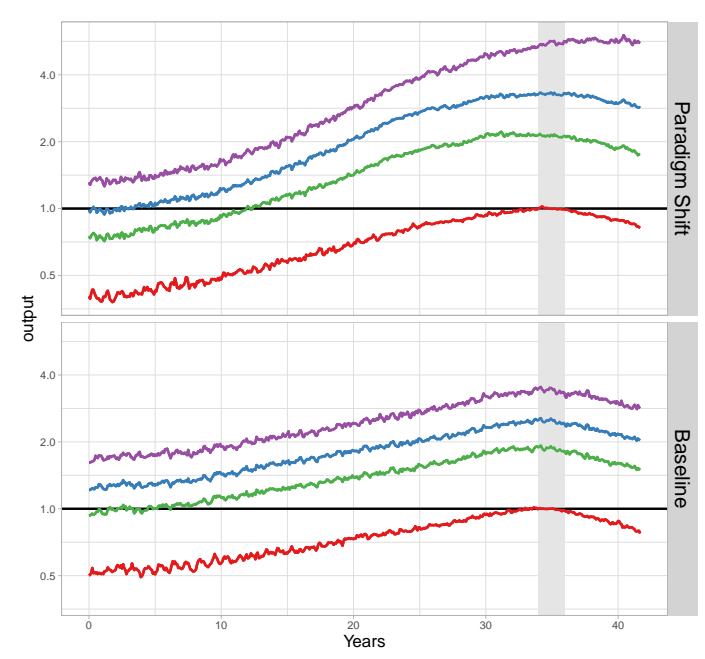

Dominant Firms over - Average - Current Top $4-$ High Tech - Low Tech

(b) $\gamma_{c}=16$

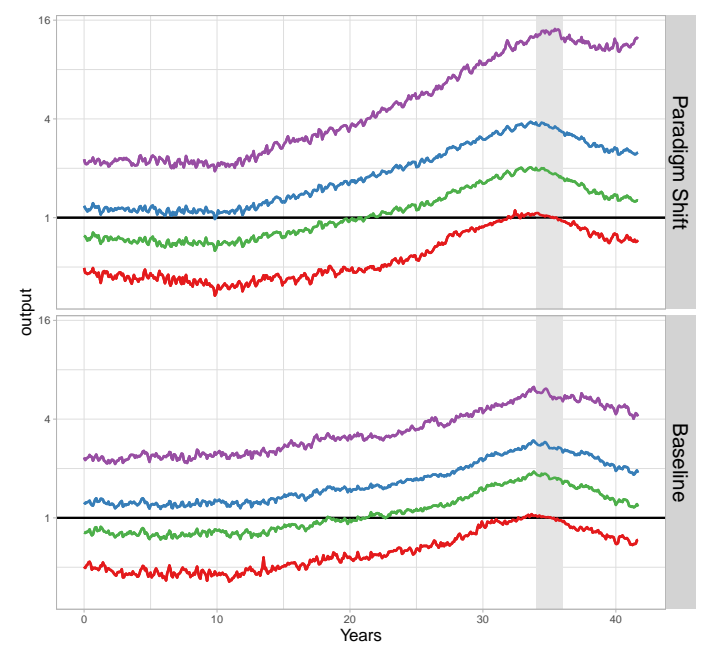

Dominant Firms over - Average - Current Top $4-$ High Tech - Low Tech

(d) $\gamma_{c}=19$

Figure F2. Relative performance in output with variation in $\gamma_{c}$. Definitions correspond to Figure 4. 


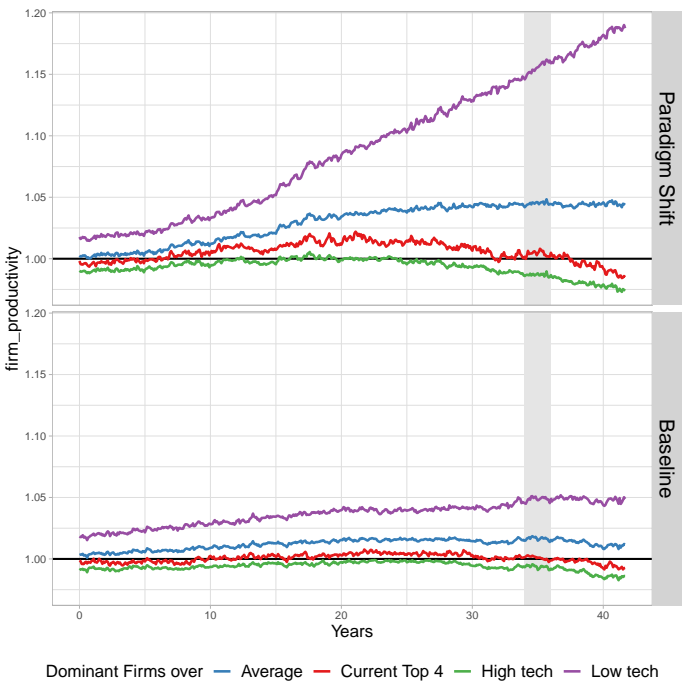

(a) $\gamma_{c}=15$

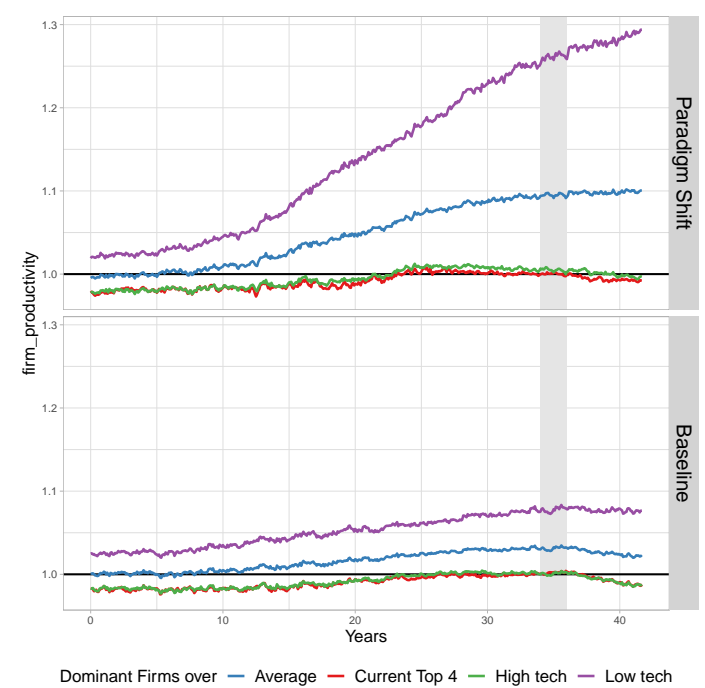

(c) $\gamma_{c}=18$

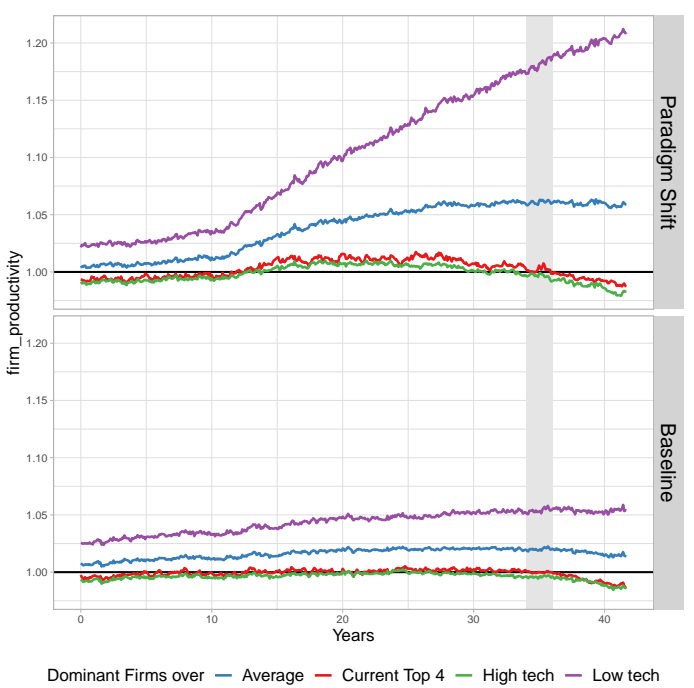

(b) $\gamma_{c}=16$

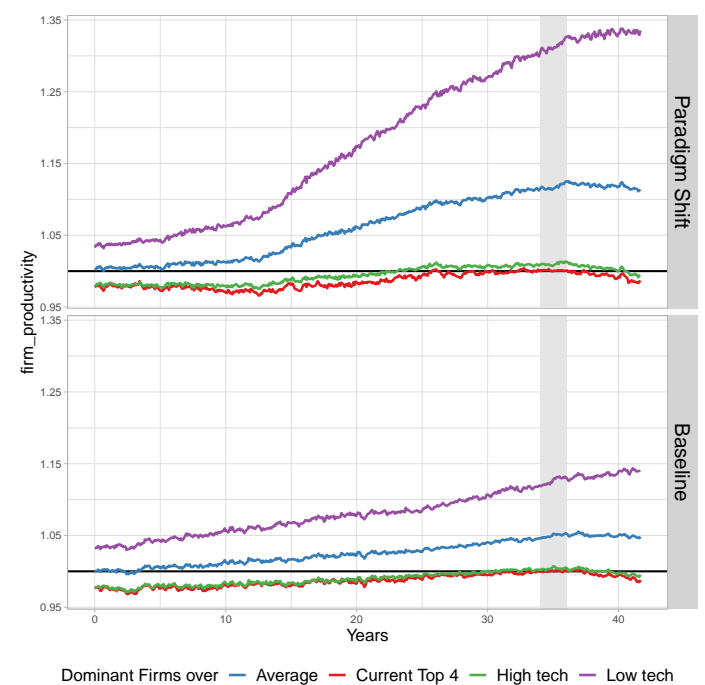

(d) $\gamma_{c}=19$

Figure F3. Relative performance in productivity with variation in $\gamma_{c}$. Definitions correspond to Figure 4. 